\title{
Simulation of Carbon Dioxide Injection at the FutureGen2.0 site: Class VI Permit Model and Local Sensitivity Analysis
}

S.K. White, Z.F. Zhang, and M. Oostrom* 


\section{Abstract}

Numerical simulation was conducted to evaluate supercritical $\mathrm{CO}_{2}\left(\mathrm{scCO}_{2}\right)$ storage in the Mt. Simon sandstone at the FutureGen 2.0 site in Morgan County, Illinois. The simulations illustrate the recent modeling effort conducted to successfully obtain a Class VI permit under the Underground Injection Control Program of the U.S. Environmental Protection Agency. The scCO2 was injected into a highly stratified reservoir, distributed among four lateral wells. Results show that each of the multiple reservoir layers with low permeability traps a fraction of the $\mathrm{scCO}_{2}$ beneath it so that the injected $\mathrm{scCO}_{2}$ does not reach the top of the reservoir by the end of the simulation period. Hence, all of the injected $\mathrm{scCO}_{2}$ is considered to be safely trapped by the stratified structure within the reservoir. A local sensitivity analysis (LSA) was conducted for injectivity and plume size at the end of the 20 year injection period. The LSA indicates that the imposed initial conditions and the hydraulic properties of the injection layer contribute the most to the sensitivity. Overall, the simulation outputs are very sensitive to only a small fraction of the inputs. However, the parameters that are important for controlling $\mathrm{CO}_{2}$ injectivity are not the same as those controlling the plume area. The three most sensitive inputs for injectivity are the horizontal permeability and the residual aqueous saturation of the injection layer, and the initial fracture-pressure gradient. For the plume area, the most sensitive inputs are the horizontal permeability of the injection layer and the residual aqueous saturation of the two adjacent layers above the injection layer. The advantages of requiring just a single set of simulation results, scalability to the proper parameter errors, and straightforward calculation of the composite sensitivities make the proposed analysis attractive for guiding site characterization, injection well design, estimating Area of Review uncertainty and, and monitoring network design. 
Key Words: Carbon Sequestration; Reservoir Simulation, Modeling, Local Sensitivity Analysis

\section{Highlights:}

- The multiphase simulation used to obtain a Class VI permit for the FutureGen2.0 site is presented.

- The injected $\mathrm{scCO}_{2}$ (22 MMT over 20 years) does not reach the top of the reservoir by the end of the simulation period.

- The $\mathrm{CO}_{2}$ injectivity and plume area very sensitive to only a small fraction of the inputs.

- The local sensitivities are additive for the calculation of composite sensitivities.

- The analysis is attractive for, among others, guidance of well and monitoring network design.

\section{Introduction}

Combatting global warming through the reduction of anthropogenic carbon dioxide $\left(\mathrm{CO}_{2}\right)$ emissions into the atmosphere has emerged as a key challenge for society (Huang et al., 2014). The option of carbon sequestration in deep formations (e.g., coalbeds, saline aquifers, and oil and gas reservoirs) is considered to be a method to reduce the adverse impacts of $\mathrm{CO}_{2}$ emissions. Of the deep formations, saline aquifers, widely distributed around the globe in sedimentary basins, offer the largest storage potential. Important examples are the Mt. Simon Sandstone in the Illinois Basin (Person et al., 2010), the saline aquifers in the Alberta Basin (Bachu et al., 1994), and the Carrizo-Wilcox aquifer in the Texas Gulf Coast Basin (Nicot, 2008). Geologic storage as a $\mathrm{CO}_{2}$ mitigation strategy will only be workable if long-term secure containment can be assured in formations with sufficient low-permeability caprocks preventing upward migration (Pruess and Nordbotten, 2011).

Numerical simulation of the injection and redistribution of supercritical $\mathrm{CO}_{2}\left(\mathrm{scCO}_{2}\right)$ is important to determine storage capacity (Mathias et al., 2013), injectivity (Rasmussen et al., 2014), formation and basin pressure (Chadwick et al., 2009), plume extent and shape (Bandilla et al., 2012; Zhang et al., 2015), leakage potential (Pruess and Garcia, 2002), well placement optimization (Cameron and Durlovsky, 2012), model gridding (Yamamoto and Doughty, 2011), salt precipitation (Giorgis et al., 2007) and impacts on regional groundwater flow (Yamamoto et 
al., 2009). In addition, multiphase modeling in the U.S.A. has become a necessary tool for regulatory compliance such as under the EPA Rule for Class VI Underground Injection Wells (USEPA, 2011; 2013).

Ideally, numerical simulators should have the ability to represent the four primary mechanisms identified for $\mathrm{CO}_{2}$ trapping (Doughty, 2010): stratigraphic or structural, residual, dissolution, and mineral. Given that mineral trapping in saline reservoirs typically occurs over very long time scales (Pruess et al., 2004), the first three mechanisms, often referred to as hydrodynamic trapping, dominate plume behavior during injection and immediately thereafter over a hundred-year time scale (Doughty, 2010). Given its near-future dominance, most of the recent modeling contributions (e.g., Doughty, 2010; Sung et al., 2014) focus on hydrodynamic trapping mechanisms, although modeling the combined effects of multiphase flow and reactive transport are becoming more prevalent (Liu et al., 2011; Bacon et al., 2014).

Some of the modeling work to date involves $\mathrm{scCO}_{2}$ injection in homogeneous and relatively simple heterogeneous configurations (e.g., Birkholzer et al., 2009; Kim et al., 2012; Mathias et al., 2013). With increasing computational power, researchers have started to simulate flow and transport in heterogeneous reservoirs at the plume and basin scales (Benisch and Bauer, 2013; Dutta and Zoback, 2012; Pham et al., 2013; Person et al., 2013;Yamamoto et al., 2009; Senel et al., 2013; Sung et al., 2014; Zhou and Birkholzer, 2010; Doughty, 2010). The recent modeling applications comprise evaluations of injection into aquifers in Norway (Pham et al., 2013), Taiwan (Sung et al., 2014), Germany (Benish and Bauer, 2013), and Japan (Yamamoto et al., 2009 ) as well as at several U.S. sites. Sites selected for simulation of $\mathrm{scCO}_{2}$ injection include the Powder River Basin in Wyoming (Dutta and Zoback, 2012), the Kimberlina aquifer in California (Doughty, 2010), the Frio brine pilot site in Texas (Doughty et al., 2008) and several sites in the Illinois Basin (Bandilla et al, 2012; Person et al., 2010; Senel et al., 2014; Zhou et al., 2010). The sandstone of interest in most of the Illinois Basin studies is the Mt. Simon, a siliciclastic unit of Cambrian age that is present throughout the basin. According to Person et al. (2010), the Mt. Simon sandstone generally has sufficient permeability and porosity for favorable injectivity.

The Mt. Simon in the Illinois Basin is also the primary target of $\mathrm{scCO}_{2}$ injection at the FutureGen 2.0 site. Under the terms of a cooperative agreement with the Department of Energy (DOE), the FutureGen Industrial Alliance (Alliance) was responsible for locating a suitable site, and executing the design, construction and operation of the FutureGen $2.0 \mathrm{CO}_{2}$ Pipeline and 
Storage Project. The primary objective of the project was to site, design, construct, and operate a pipeline and storage reservoir to be fully integrated with the FutureGen 2.0 Oxy-Combustion Large Scale Project, with sufficient capacity to transport, and sequester up to 1.1 million metric tons (MMT) per year of $\mathrm{scCO}_{2}$ into the Mt Simon Sandstone for a duration of 20 years, resulting in storage of a total of $22 \mathrm{MMT} \mathrm{scCO}_{2}$ (Gilmore et al., 2016; Vermeul et al., 2016). Site characterization indicated the presence of a relatively thin, high-permeability injection interval within the Mt. Simon sandstone, leading the project to consider horizontal injection well configurations for delivering $\mathrm{scCO}_{2}$ to the subsurface storage reservoir. Preliminary simulations showed that horizontal (lateral) wells originating from a common well pad were found to provide a viable alternative that would minimize the environmental impact of well drilling, while delivering $\mathrm{scCO}_{2}$ at the required injection rates. This approach is consistent with the recommendations by Okwen et al. (2011) for injection into reservoirs that are injectivity constrained due to a limited vertical thickness. For such formations, a significantly higher $\mathrm{CO}_{2}$ injection rate can be achieved without exceeding a maximum allowable pressure (Vilarrasa, 2014). The consideration of horizontal injection is a deviation from the vertical modeling injection approaches considered so far for Mt. Simon applications (Person et al., 2010; Senel et al., 2014; Zhou et al., 2010; Zhou and Birkholzer, 2010). Horizontal wells have been used successfully at other $\mathrm{CO}_{2}$ storage sites such as the In Salah (Rutqvist et al., 2010; Drucran et al., 2011; Deflandre et al., 2011) and the Sleipner sites (Cavanagh, 2013; Cavanagh and Nazarian, 2014; Singh et al., 2010).

Sensitivity analysis evaluates the importance of input parameters on model outputs and may serve as a basis for developing reduced-order models. The sensitivity of model input is quantified using either local or global approaches. A global sensitivity analysis (GSA) considers the entire parameter space and may account for interactions among parameters in system responses depending on the selected approach. For a given output in a GSA, the sensitivity of different inputs can be directly compared. To consider model non-linearity and parameter interaction, usually Monte Carlo simulation is performed to account for the uncertainty in each individual parameter and combinations of parameters. This type of investigation often requires a large amount of simulation runs, which may be somewhat reduced using Latin hypercube sampling (McKay et al., 1979). For example, Yoshida et al. (2016) investigated the sensitivity of 
four parameters in the relative permeability relationship using 1000 Monte Carlo realizations with Latin Hypercube sampling.

Most sensitivity studies related to $\mathrm{CO}_{2}$ sequestration use the approach where only one parameter is changed at a time and interactive effects of parameters are not considered (e.g. Birkholzer et al., 2009; Zhao et al., 2010; Han et al., 2011. Birkholzer et al. (2009) evaluated the sensitivity of seal permeability and rock compressibility on pressure response during $\mathrm{CO}_{2}$ injection by assigning a series of values to each of the input parameters. Zhao et al. (2010) analyzed the sensitivity of reservoir permeability and anisotropy on $\mathrm{CO}_{2}$ storage capacity. Han et al. (2011) studied the contribution of five different parameters to the residual (capillary) trapping and solubility trapping mechanisms. Sarkarfarshi et al. (2014) investigated sensitivity of the plume interface location, the maximum breakthrough distance of $\mathrm{CO}_{2}$, and the moment of inertia of the $\mathrm{CO}_{2}$ plume with respect to intrinsic physical system parameters and parameters introduced in constitutive relationships at a hypothetical site.

A local sensitivity analysis (LSA) uses the partial derivative of the representative output variable with respect to selected input parameters (e.g., Castilloa et al., 2004; Birkholzer et al., 2011; Wainwright et al., 2013; Zhang et al., 2014). Generally, partial derivatives over different input parameters often have different units and can therefore not be directly compared. To overcome this issue, a variety of methods have been proposed. Birkholzer et al. (2011) scaled the partial derivatives by the expected input parameter uncertainty and by the inverse of the acceptable variability in the output variables. Alternatively, Zhang et al. (2014) scaled the injectivity and plume size for the various scenarios by the base case values.

Generally, the required number of simulations $(N)$ is linearly proportional to the number of parameters $(k)$ for a LSA, while $N$ is exponentially proportional to $k$ for a GSA. An LSA is accurate if the response of the output to an input is linear. Otherwise, a LSA may not represent the sensitivity in the overall parameter space. In spite of this limitation, a LSA might still be advantageous for ranking the importance of model inputs because of its simplicity and low computation cost. It should be noted that some researchers (e.g., Foglia et al., 2009) argued that many models of natural systems are linear enough for a useful LSA. Additionally, the local sensitivities for the inputs are additive and hence the sensitivity of a set of parameters (e.g., associated with a certain zone or condition) can be calculated without conducting further simulations (Zhang et al., 2014). When $N$ becomes very large (e.g., 100s or more) and the 
computation time of each run can be very long (e.g., days to weeks), it may be impractical to complete a GSA in a desired period. Under certain conditions, a LSA and GSA hybrid idea might be considered. Instead of eliminating unimportant parameters arbitrarily, a LSA can first be conducted to rank the inputs quantitatively. A GSA can then be conducted for the most important inputs.

The main objectives of this work are twofold: (1) to present the multiphase modeling effort required to obtain a Class VI permit for injection into the Mt. Simon sandstone at the FutureGen 2.0 site using multiple horizontal injection wells, and (2) to present a novel LSA for injectivity and plume area. The multiphase modeling effort considers the effects of stratigraphic, residual, and dissolution trapping in a heterogeneous system where buoyancy flow might be significant.

\section{Methods}

\subsection{Class VI Permit Simulation}

\subsubsection{Conceptual Model}

Characterization of the site was based on regional geologic information along with data from regional boreholes and a stratigraphic well drilled at the site. These data were used to generate a $161 \mathrm{~km} \times 161 \mathrm{~km}(100 \mathrm{mi} \times 100-\mathrm{mi})$ geologic model for the site representing the major stratigraphic units and their regional dip of approximately 0.25 degrees in the east-southeast direction (Gilmore et al., 2016). The depths and thickness of major geological formation were determined by the knowledge of regional geology. Further refinement, resulting in a total of 51 vertical layers representing zones of similar hydrogeologic properties, was based on wireline logs and core data from the stratigraphic well. These layers, shown in Figure 1a, define the computational model domain for the Class VI permit model. The domain comprises the injection target (Mt. Simon Sandstone and the overlying Elmhurst Sandstone member of the Eau Claire Formation), the primary confining zone (Lombard and Proviso members of the Eau Claire Formation) the Ironton and Galesville Sandstones, and the secondary confining zone (Davis Dolomite and Franconia Formation). Because site-specific data were available only from the single stratigraphic well, it was assumed that the hydrogeologic layers defined for the model were laterally continuous and homogeneous within each layer. The thickness of the layers varied 
spatially and were determined by the scaling the thickness of the corresponding formation (Figure 1).

\subsubsection{Hydrogeologic Properties}

A number of data sources and methods were used to assign properties to the hydrogeologic layers. Available data sources included results from continuous wireline surveys (compensated magnetic resonance [CMR], Elemental Analysis [ELAN]), standard and sidewall cores (SWCs), and hydrologic tests (Modular Formation Dynamics Tester [MDT] and packer tests). Because of differences in lithology and in the borehole construction, the method used to assign properties varied for different vertical zones of the conceptual model. For model layers within the injection zone, a correlation/calibration approach was applied. Wireline log CMR- and ELAN-computed permeability model responses were first correlated with and then calibrated to rotary sidewall and core plug permeability results. The correlation process was facilitated using natural gamma ray responses and clay or shale abundance to establish correlation data sets. This calibration provided a continuous permeability estimate (curve permKCal) over the entire injection reservoir section. The calibrated permeability response was then slightly adjusted, or scaled, to match the composite results obtained from the hydrologic packer tests over uncased intervals. For injection reservoir model layers within the cased portion of the well, no hydrologic test data were available, therefore core-calibrated ELAN log response was used directly in assigning average model layer permeabilities.

For layers in the confining zones, only well-log and core data were used to determine hydrologic properties, as no hydrologic or MDT test data were available. Because the average log-derived permeabilities (permKCal wireline from ELAN $\log$ ) for most of the caprock layers were at or below $0.01 \mathrm{mD}\left(9.87 \times 10^{-18} \mathrm{~m}^{2}\right)$, an alternate approach was applied. For each model layer the core data were reviewed, and a simple average of the available horizontal Klinkenburg permeabilities was then calculated for each layer. Core samples that were noted as having potential cracks and/or were very small were eliminated if the results appeared to be unreasonable based on the sampled lithology. If no core samples were available and the arithmetic mean of the PermKCal was below $0.01 \mathrm{mD}$, this value was applied. Figure 2 a shows the distribution of horizontal permeability with depth. Literature-based permeability anisotropy values were used to assign vertical permeability values to each layer based on the horizontal 
permeability values. To assign layer porosities, first the ELAN porosity log results were calibrated to sidewall core measurements, based on linear regression relationships developed for both PIGN (Gamma-Neutron Porosity) and PHIT (Total Porosity). The porosity distribution for the permit model is presented in Figure 3a.

\subsubsection{Numerical Model}

Numerical simulation of $\mathrm{scCO}_{2}$ injection into deep geologic reservoirs requires the modeling of complex, coupled hydrologic, chemical, and thermal processes, including multi-fluid flow and transport, partitioning of $\mathrm{scCO}_{2}$ into the aqueous phase, and chemical interactions with aqueous fluids and rock minerals. The simulations conducted for this investigation were executed using the STOMP-CO2 simulator (White et al., 2012). STOMP-CO2 has been verified against other codes used for simulation of geologic disposal of $\mathrm{CO}_{2}$ as part of the GeoSeq code intercomparison study (Pruess et al., 2004).

The model domain consists of the injection zone (Mount Simon and Elmhurst), the primary confining zone (Lombard and Proviso), the Ironton-Galesville, and the secondary confining zone (Davis-Ironton and Franconia). Preliminary simulations were conducted to determine the extent of the model domain so that lateral boundaries were distant enough from the injection location so as not to influence the model results. The three-dimensional, boundary-fitted numerical model grid was designed to have constant grid spacing with higher resolution in the area influenced by the $\mathrm{scCO}_{2}$ injection (4.8- by $4.8 \mathrm{~km}$ area), with increasingly larger grid spacing moving out in all lateral directions toward the domain boundary. The permit model grid contains 125 nodes in the $x$-direction, 125 nodes in the $y$-direction, and 51 nodes in the $z$-direction for a total number of nodes equal to 796,875 . The geocellular model was queried at the node locations of the numerical model to determine the elevation of each surface for the major hydrogeologic units at the numerical model grid cell centers (nodes) and cell edges. Then each of those layers was subdivided into the refined model layers by scaling the thickness to preserve the total thickness of each stratigraphic unit. Once the vertical layering was defined, material properties were mapped to each node in the model.

Prior to injection, the reservoir was assumed to be under hydrostatic conditions with no regional or local flow conditions. Therefore, the hydrologic flow system was assumed to be at steady state until the start of injection. Initial conditions for pressure, temperature and salinity 
based on site specific data were specified at a reference depth using the hydrostatic initial condition option, allowing STOMP-CO2 to calculate and assign the initial conditions to all the model nodes. A temperature gradient was specified based on the geothermal gradient, but the initial salinity was considered to be constant for the entire domain. A summary of the initial conditions is presented in Table 1. Boundary conditions were established with the assumption that the reservoir is continuous throughout the region and that the underlying Precambrian unit is impermeable. Therefore, the bottom boundary was set as a no-flow boundary for aqueous fluids and for the $\mathrm{CO}_{2}$-rich phase. The lateral and top boundary conditions were set to hydrostatic pressure using the initial condition with the assumption that each of these boundaries is distant enough from the injection zone to have minimal to no effect on the $\mathrm{scCO}_{2}$ plume migration and pressure distribution. The simulation time was 500 years, which is well beyond the time period deemed appropriate to satisfy the U.S. EPA (2011) guidelines for multiphase modeling duration for the project's Class VI permit application. The recommended simulation period should be until plume migration ceases and until pressure differentials have dissipated to the point where injected $\mathrm{scCO}_{2}$ or formation fluids will not be able to move into an underground source of drinking water.

The STOMP-CO2 simulator uses a fully-coupled well model with a flexible well trajectory that uses a modification to the Peaceman well index $(1983,1990)$ formulation for describing the coupling between the flow rate in the well and flow rate in the reservoir as a function of well pressure, reservoir pressure, well properties, and reservoir properties (White et al. 2013). This well model allows for specification of the well trajectory and perforated intervals independent of grid spacing and without excessive grid refinement that may limit the computational efficiency. Figure 4 shows the well locations in 3D view and plan view. Injection into four lateral wells with a well-bore radius of $11.43 \mathrm{~cm}$ (4.5 in) was modeled with the lateral leg of each of the four wells located within the highest permeability layer of the injection zone to maximize injectivity. The lengths of each lateral well section are shown in Table 2. The wells modeled in this case were open boreholes with part of the curved portion being open and thereby represented in the model in addition to the lateral legs. The orientation and lateral length of the wells was chosen so that the resulting modeled $\mathrm{scCO}_{2}$ plume would avoid areas underlying those deemed to be sensitive on the surface. The $\mathrm{scCO}_{2}$ mass injection rate was distributed among the four injection wells as shown in Table 2, for a total injection rate of $1.1 \mathrm{MMT} / \mathrm{yr}$ for 20 years. The injection 
rate was assigned to each well proportional to the well's lateral length. A maximum injection pressure of $15.53 \mathrm{MPa}$, based on 90 percent of the fracture pressure, was assigned at the top of the open interval which is at a depth of $1173.5 \mathrm{~m}$ below ground surface.

The Brooks and Corey (1964) model was used to describe the relationship between capillary pressure and aqueous saturation:

$$
\bar{S}_{l}=\left\{\begin{array}{c}
\left(P_{c}^{e} / P_{c}\right)^{\lambda} \text { if } P_{c}>P_{c}^{e} \\
1 \text { otherwise }
\end{array}\right.
$$

where $P_{c}$ is the capillary pressure $(\mathrm{Pa}), P_{c}^{e}$ is gas entry pressure, $\lambda$ is the pore-size distribution parameter, and $\bar{S}_{l}$ is effective aqueous saturation defined as

$$
\bar{S}_{l}=\frac{S_{l}-S_{l r}}{1-S_{l r}}
$$

where $S_{l}$ and $S_{l r}$ are the actual saturation and residual saturation of the aqueous phase, respectively. To describe the $P_{c}\left(S_{l}\right)$ relationships for the full saturation range, the aqueous phase is conceptualized as a combination of capillary water and absorbed water (Webb, 2000; Zhang, 2011). The $P_{c}\left(S_{l}\right)$ relationships is divided into two segments separated by the critical capillary pressure, $P_{c}^{m}$, a point at which the tangent line of the relation passes the point corresponding to the oven-dry condition, $P_{c}^{d}$, which is about $10^{9} \mathrm{~Pa}$ (Rossi and Nimmo, 1994). Capillary pressure data determined from site-specific cores were not available at the time the model was constructed. However, tabulated capillary pressure data were available for several Mount Simon gas storage fields in the Illinois Basin with data for the Manlove Hazen well to be the most complete. Therefore, these aqueous saturation and capillary pressure values were plotted and a user-defined curve fitting was performed to generate Brooks-Corey parameters (Eq. 1) for four different permeability ranges. These parameters were then assigned to layers based on a permeability range as shown in Table 3. Combined with the Burdine (1953) relative permeability model, the relative permeability relations for the aqueous phase, $k_{r l}$, and for the non-aqueous phase, $k_{r g}$, are 


$$
\begin{aligned}
& k_{r l}=\left(\bar{S}_{l}\right)^{3+2 / \lambda} \\
& k_{r g}=\left(1-\bar{S}_{l}\right)^{2}\left(1-\bar{S}_{l}{ }^{1+2 / \lambda}\right)
\end{aligned}
$$

STOMP-CO2 includes effects of gas entrapment during aqueous-phase imbibition paths. For this application, gas entrapment occurs after injection ceased as brine displaces $\mathrm{scCO}_{2}$. Gas effective residual saturations are computed using an empirical relationship developed by Land (1968) for immiscible fluids, using a maximum entrapped gas saturation of 0.2 , which is a typical value for a water-wet system (Oostrom et al., 2005). The gas entrapment routine is similar to the full hysteretic model used by Doughty (2007) to model injection into a heterogeneous formation. Although Doughty (2007) demonstrated the importance of using hysteretic approaches for post-injection periods when the $\mathrm{scCO}_{2}$ plume moves upward and updip due to buoyant forces, most field-scale modeling application are non-hysteretic (Middleton et al., 2012; Mituku and Bauer, 2013; Yamamoto et al., 2009; Zhou et al., 2010)

\subsection{Local Sensitivity Analysis}

\subsubsection{Method Description}

In numerical simulation of $\mathrm{CO}_{2}$ injection and redistribution, the output, $Y_{0}$, such as injectivity or plume area, is a function of $N$ inputs (i.e., $X_{l}$ through $X_{N}$ ). For a base (or reference) case (subscript 0), the function can be written as

$$
Y_{0}=f\left(X_{1}, X_{2}, \ldots, X_{i}, \ldots, X_{N}\right)
$$

In a sensitivity analysis, the change in output for a case $i, \Delta Y_{i}$, to a change of an input $X_{i}, \Delta X_{i}$, is calculated as

$$
\Delta Y_{i}=Y_{i}-Y_{0}=f\left(X_{1}, X_{2}, \ldots, X_{i}+\Delta X_{i}, \ldots, X_{N}\right)-f\left(X_{1}, X_{2}, \ldots, X_{i}, \ldots, X_{N}\right)
$$

In this paper, the local sensitivity coefficient for each of the inputs, $C_{i}$, is defined as follows:

$$
C_{i}=\Delta Y_{i} / Y_{0}=Y_{i} / Y_{0}-1
$$

If $\mathrm{C}_{\mathrm{i}}>0$, the change in input $X_{i}$ has a positive impact on $Y_{i}$. Vice versa, if $\mathrm{C}_{\mathrm{i}}<0$, the change in input $X_{i}$ has a negative impact on $Y_{i}$. Hence, an input has the largest sensitivity when the absolute value of $C_{i}$ is the largest. The definition of $C_{i}$ in Eq. (5) is simpler than that used by Foglia et al. (2009) and Wainwright et al. (2013) because no weighting factors are required. In addition, only $N+1$ simulations are needed to compute $C_{i}$ for each of the $N$ model inputs. To compute $C_{i}$ for 
each of the inputs, $\Delta X_{i}$, must be determined a priori. To make the analysis meaningful, $\Delta X_{i}$ should reflect the uncertainty of the input $X_{i}$. In our approach, the standard deviation of $X_{i}, \sigma_{x i}$, is used if $X_{i}$ is normally distributed (ND), or the standard deviation of $\ln \left(X_{i}\right), \sigma_{l n x i}$, is used if $X_{i}$ has a $\log$ normal distribution (LND). However, often the standard deviations are unknown beforehand and an initial best guess has to be used, such as the measurement error of $X i$. Using this approach, $\Delta X_{i}$ will be a constant for ND inputs (e.g., porosity) and a fraction of $X_{i}$ (i.e., $\Delta X_{i}=b X_{i}$, where $b$ is a constant) for LND inputs (e.g., permeability).

When the impact of a parameter is linear, the local sensitivity can be directly scaled to estimate the response of predictions at a different value of parameter uncertainty using the results of the completed simulations. However, if the impact of a parameter is nonlinear, the accuracy of the estimated sensitivity decreases with an increase in uncertainty. The scaled local sensitivity coefficient, $C_{i}^{S}$, can be estimated using either the known $\sigma_{x i}$ or $\sigma_{l n x i}$ value:

$$
C_{i}^{S}=\left\{\begin{array}{c}
C_{i} \frac{\sigma_{x i}}{\Delta X_{i}} \quad \text { for ND inputs } \\
C_{i} \frac{\sigma_{\ln x i}}{\ln \left(1+b_{i}\right)} \text { for LND inputs }
\end{array}\right.
$$

Based on the first-order approximation of the Taylor series over multiple variables, the local sensitivities to different parameters are additive, assuming that parameters are independent of one another in the model. This assumption requires that the value of an input not be calculated based on one or more of the other inputs. For example, porosity and permeability often have a good correlation. In this case, if permeability is calculated based on porosity, they are not independent. Otherwise, if they are determined separately, they can be considered to be independent. Therefore, based on the simulation results of the sensitivity to individual inputs, the composite sensitivity of a prediction to a subset of $M(M \leq N)$ inputs can be readily calculated by summing up the individual $C_{i}^{S}$ values:

$$
C^{S}=\sum_{1}^{M} C_{i}^{S}
$$

Because $\Delta X_{i}$ and $b$ can be either positive or negative, Eq. (7) may only be used if the signs of $\Delta X_{i}$ and $b$ are known because positive and negative $C_{i}^{S}$ values cancel each other. The absolute composite scaled sensitivity coefficient, $C_{a b}^{S}$, which is the maximum sensitivity for the subset or all of inputs, is the sum of the absolute values of $C_{i}^{S}$ : 


$$
C_{a b}^{S}=\sum_{1}^{M}\left|C_{i}^{S}\right|
$$

\subsubsection{Application of LSA to FutureGen2.0 Site}

To reduce simulation time in the sensitivity analysis, the LSA was applied to a slightly modified conceptual model compared to what was used for the permit modeling (Figure 1a). To reduce the number of input parameters that needed to be considered, some layers with a likely limited influence on the results were combined, resulting in 31 remaining layers, as shown in Figure 1b. The permeability and porosity distributions for the LSA reference case are shown in Figures $2 b$ and $3 b$, respectively. For the LSA simulations, the injection rate was pressure controlled at $90 \%$ of the maximum fracture pressure. For the LSA reference case, the average total injection rate for the 4 wells was about 1.1 MMT/yr, which is close to the imposed rate for the permit. We applied the LSA sensitivity approach to investigate the sensitivity of injectivity and plume area to input parameters and initial conditions. The $\mathrm{CO}_{2}$ injectivity is defined as the total mass of $\mathrm{CO}_{2}$ injected into the injection zone at a given time. The horizontal plume area is quantified by the area that contains $99 \%$ of the $\mathrm{CO}_{2}$ mass injected based on the vertically integrated mass per area (Zhang et al., 2015). Because the total $\mathrm{CO}_{2}$ mass injected was different among the simulation cases, the plume area was scaled by the injected mass of the reference case to obtain meaningful comparisons.

The sensitivities to 11 parameters, describing the physical properties of the rocks, for each of the 31 layers were investigated relative to a base (reference) case, which was the most representative case based on the characterization data available. The parameters, changes in parameter values, and the assumed standard deviation are summarized in Table 4. In total there were $341(=31 \times 11)$ parameters evaluated (Table 5). Additionally, the sensitivities to seven inputs that describe the initial conditions of the simulation were examined (Table 6). The standard deviation for each of the inputs presented in this paper was assumed for the purpose of demonstration of the LSA and the actual values may be different. There were 349 simulations performed in total for 348 inputs, including the reference case. After the completion of the simulations, the injectivity of $\mathrm{CO}_{2}$ and the plume area was calculated for each simulation at different times. The sensitivity coefficients of $\mathrm{CO}_{2}$ injectivity and plume area to each of the 348 inputs were calculated using Eqs. (5) and (6) for different times. The absolute composite 
sensitivity coefficients were then calculated using Eq. (8). The results reported here are for the injectivity and plume area at $20 \mathrm{yrs}$, the time at which injection ceased.

\section{Results and Discussion}

\subsection{Class VI Permit Simulation}

\subsection{1 $\mathrm{CO}_{2}$ Migration}

Reservoir conditions are such that the $\mathrm{CO}_{2}$-rich phase remains in the supercritical state throughout the domain and for the entire simulation period. Figure 5 shows the evolution of the $\mathrm{scCO}_{2}$ plume in the Mount Simon layer where the lateral portion of the injection wells reside. Figure 6 depicts a cutaway view along the A-A' line (see Figure 4). As indicated in Figure 6, the injection wells are open to the formation in the lateral sections (in the Mt. Simon formations) and in the lower part of the vertical section (in the Elmhurst and Lower Lombard formations). Figure 5a shows that the $\mathrm{scCO}_{2}$ plume initially forms a cloverleaf pattern as a result of the design with four lateral injection-wells. After the start of the injection, nearly all of the $\mathrm{scCO}_{2}$ resides near the wells (Figures 5a and 6a). As the injection continues, the four lobes of the $\mathrm{scCO}_{2}$ plume become wider and begin to intermingle with the adjacent lobes (see Figure $5 \mathrm{~b}$ at $5 \mathrm{yr}$ ). After that point in time, the plume keeps approximately the same shape but grows larger with time during the 20-year injection period (Figures 5c and 5d). Relatively small amounts $\mathrm{scCO}_{2}$ enter the reservoir through the open vertical sections (Figure $6 \mathrm{~b}, \mathrm{c}$, and $\mathrm{d}$ ). These figures also show that during the injection period, the $\mathrm{scCO}_{2}$ saturation is highest near the wells and decreases gradually away from the wells. The highest $\mathrm{scCO}_{2}$ saturation occurs at the tip of each of the injection wells and saturations near the center of the four wells remains relatively low. This is in part because the pressure distribution within the wells is different from that within the reservoir. Within the injection wells, the pressure drop is negligible. However, within the reservoir a large pressure gradient exists with the highest pressure occurring at the center of the four wells. Consequently, the pressure gradient between each well and the surrounding reservoir is the largest at the ends of the wells. These observations during injection are consistent with the findings by Okwen et al. (2011). 
In the 50 years after injection, the $\mathrm{scCO}_{2}$ saturations generally decrease in the layer with the lateral wells although the extent of the plume does not change considerably (Figure 5e). This is because $\mathrm{scCO}_{2}$ migration during the initial redistribution phase is primarily vertically upwards in the Mount Simon formation, due to buoyancy effects, with minimal horizontal movement of the plume (Figure 6e). Later in time, Figure $5 \mathrm{f}$ shows that $\mathrm{scCO}_{2}$ saturations in the injection layer (MS11) reduce to values mostly less than 0.3, indicating that most of the mobile $\mathrm{scCO}_{2}$ has migrated upwards, leaving primarily entrapped $\mathrm{scCO}_{2}$ behind. Figure $6 \mathrm{f}$ indicates that a considerable amount of mobile $\mathrm{scCO}_{2}$ has collected just below the Elmhurst formation. Because the reservoir is stratified, with considerable variations in permeability and entry pressures, most of the $\mathrm{scCO}_{2}$ does not reach the interface between the Elmhurst and the Mount Simon and no $\mathrm{scCO}_{2}$ has moved above the top of the Lower Lombard by year 500 (Figure 6f). The results shown in Figure 6 indicate that reservoir stratification helps to trap the injected $\mathrm{scCO}_{2}$. When a fine layer overlays a coarse layer, the $\mathrm{scCO}_{2}$ in the coarse layer must overcome an entry pressure before it can enter the fine layer. As a result, $\mathrm{scCO}_{2}$ tends to accumulate below the fine-overcoarse interfaces. The $\mathrm{scCO}_{2}$ plume as shown in Figure 6 has an irregular shape in the cutaway view, distinctive from the typical funnel-shaped plumes that are predicted to occur in a homogeneous reservoir. These results suggest that models using a homogeneous medium to represent a heterogeneous medium and those that ignore capillary effects may have considerable error in the results and overestimate the risk of leakage.

The use of lateral wells provides flexibility in controlling the features of the $\mathrm{scCO}_{2}$ plume, (e.g., the plume shape and the dominant direction of plume development). Because the lengths and injection rates of the two northern wells (i.e., wells \#1 and \#4) are less than those of the two southern wells (i.e., wells \#2 and \#3), the $\mathrm{scCO}_{2}$ plume extent is greater in the southern half relative to the center of the injection wells (Figure 6). The placement of the lateral portion in the rock layer with the highest permeability (i.e., MS11) maximizes the injectivity. Additionally, the use of multiple injection wells provides flexibility for well maintenance. For instance, while one well is undergoing maintenance, the $\mathrm{scCO}_{2}$ can be injected through the other three wells.

Although the reservoir has a dip of 0.25 degrees to the southeast, it appears that this has little impact on the transport of $\mathrm{scCO}_{2}$ during the injection and post-injection period. This is different from the commonly assumed up-dip movement of the $\mathrm{scCO}_{2}$ plume. The reasons for the limited up-dip movement are related to the heterogeneous nature of the reservoir in combination with the 
relatively small dip angle ( 0.25 degrees). In a homogeneous reservoir, at the tip of a scCO plume advancing under a sloping caprock, water flow is mostly downward rather than upward (Pruess and Nordbotten, 2011). The plume advances up-dip because of a collapse of the groundwater column ahead of the plume tip. However, it is more difficult for brine to move vertically in a stratified reservoir than in a homogeneous medium. Pruess and Nordbotten (2011) also pointed out that the speed of up-dip plume advancement is slower in an anisotropic medium.

\subsubsection{Plume Extent}

The footprint of the $\mathrm{scCO}_{2}$ plume is typically defined by the maximum radial extent based on the $\mathrm{scCO}_{2}$ saturation (Court et al., 2012; Doughty, 2010; Zhou et al., 2010). The figures in the previous section show that over time, the plume becomes rather irregular as a result of migration through layers with different hydraulic properties. Furthermore, due to the lateral injection scheme, the layer containing the injection wells still has the largest $\mathrm{scCO}_{2}$ saturation footprint 50 years post-injection (Figure 6e), but the extent at later times is determined by the $\mathrm{scCO}_{2}$ distribution in layers higher in the reservoir (Figure 6f). These observations illustrate that only the $\mathrm{scCO}_{2}$ saturation in the layer with the large plume extent matters in determining the plume size and that this layer might change over time (Zhang et al., 2015). To overcome some of the issues related to delineation of plumes based on $\mathrm{scCO}_{2}$ saturations, Zhang et al. (2015) proposed a method based on determining the vertically integrated mass of $\mathrm{scO}_{2}$ per area of ground surface (VIMPA). The main advantage of this approach is that the plume size is related to the distribution of mass (both separate phase and dissolved $\mathrm{CO}_{2}$ ), removing potential bias introduced by high permeability layers (Zhang et al., 2015). Applying the VIMPA approach to the simulation results yields distributions shown in Figure 7 for $\mathrm{scCO}_{2}$ directly after injection $(t=20$ years) and 50 years post injection ( $t=70$ years). Both distributions in Figure 7 contain 100\% of the $\mathrm{scCO}_{2}$ mass. A comparison of Figure 7 with the $\mathrm{scCO}_{2}$ saturation distribution in the injection layer (Figure 5) shows that the general shape is the same for both the mass and saturation distribution. However, in contrast with the considerable changes over time observed for the saturation distributions in the layer containing the wells (Figure 6d and 6e), the vertically integrated mass distributions show relatively minor changes after cessation of the injection. These results indicate limited horizontal plume spreading and migration of $\mathrm{scCO}_{2}$ out of the injection layer due to buoyancy. 
The VIMPA approach allows for the calculation of plume areas for fractions of the injected mass, as shown in Figure 8. The figure confirms that the $\mathrm{scCO}_{2}$ plume size barely changes after the injection ceases. In fact, a minor plume size reduction is predicted post injection, in part due to dissolution and $\mathrm{scCO}_{2}$ traveling mostly vertically through the reservoir. Figure 8 also indicates that a small mass fraction on the plume edges accounts for relatively large differences in the plume size. For instance, the plume area $\left(15 \mathrm{~km}^{2}\right)$ containing $95 \%$ of the $\mathrm{scCO}_{2}$ mass after 500 years is only $80 \%$ of the plume area $\left(18.6 \mathrm{~km}^{2}\right)$ containing $100 \%$ of the mass.

Injected $\mathrm{scCO}_{2}$ partitions in the reservoir between the free (or mobile) gas, entrapped gas, and aqueous phases. As discussed in the Introduction, sequestering $\mathrm{scCO}_{2}$ in deep saline reservoirs occurs through four mechanisms: 1) structural trapping, 2) aqueous dissolution, 3) hydraulic or residual trapping, and 4) mineralization. Mineralization is the chemical reaction that transforms formation minerals to carbonate minerals. This process was not simulated in this case and hence is not discussed here. Figure 9 shows the simulated mass distribution of injected $\mathrm{scCO}_{2}$ over time, demonstrating that the injection rate of $1.1 \mathrm{MMT} / \mathrm{yr}$ can be attained with the four lateral injection wells. During the injection phase, the $\mathrm{CO}_{2}$ is either mobile or dissolved in brine. The mobile phase fraction reaches its maximum value at the end of the injection period at $85 \%$ and reduces gradually to $52 \%$ after 500 years. The dissolved mass fraction is about $15 \%$ at the end of the injection period, and slowly increases to $27 \%$ after 500 years. Hydraulic trapping begins to take place once injection ceases, resulting in about $17 \%$ of the total $\mathrm{CO}_{2}$ mass being immobile after 100 years and $21 \%$ after 500 years. The result that more than $50 \%$ of the injected mass is still in mobile form after 500 years is related to the stratigraphy and the small dipping angle ( 0.25 degrees). Dougthy (2010) showed that in a formation with a 7-degree angle, the transformation from mobile $\mathrm{scCO}_{2}$ to trapped and dissolved was much faster, with a predicted disappearance of the mobile phase within 100 years.

In a homogeneous reservoir, a $\mathrm{scCO}_{2}$ pool is typically predicted to form below the caprock and structural trapping provides the long-term retention of the buoyant gas phase in the pore space of the reservoir rock. However, in the stratified reservoir under consideration, each of the multiple reservoir layers with low permeability and high entry pressure traps a fraction of the $\mathrm{scCO}_{2}$ beneath it. When there are a sufficient number of fine-over-coarse interfaces, the structural trapping due to this type of layering can prove to be effective even in the absence of an impermeable caprock layer directly above the reservoir. As discussed in the previous section, 
most of the injected $\mathrm{scCO}_{2}$ has not reached the top of the reservoir by the end of the simulation period $\left(t=500 \mathrm{yr}\right.$ ). Hence, during this time period, it was shown that all of the injected $\mathrm{scCO}_{2}$ would be safely trapped within the reservoir.

\subsection{3 $\mathrm{CO}_{2}$ Pressure}

The pressure within the injection well for each of the four wells is shown in Figure 10. Well pressure is reported at the top of the open interval and once injection ceases reflects the formation pressure at the node within which the well is located. Therefore, the well pressure reflects the injection pressure during the injection period and the pressure of the $\mathrm{scCO}_{2}$ in the well after injection ceases. The injection pressure in each well is capped by a maximum allowed value, which is $15.53 \mathrm{MPa}$, set to be at $90 \%$ of the fracture pressure. For all four injection wells, the estimated maximum injection pressure was between 15.18 and 15.40 psi, less than the maximum allowed pressure. This means that injection is controlled by the injection rate during the 20-year period of injection for all the wells. During the injection period, the well pressure increases and approaches the maximum value at the time the injection ceases. These results are in agreement with many other investigations (e.g., Birkholzer et al., 2011; Cihan et al., 2013; Mathias et al. 2011a,b; Zhou et al., 2010). Right after the injection ceases the well pressure decreases sharply and then slowly decreases asymptotically to the initial pressure.

The pressure build-up, $\Delta \mathrm{P}$, at a given location is the difference between the pressure at a given time and the initial pressure before injection was initiated. Figure 11 shows the pressure build-up at $t=20$ years when the $\mathrm{scCO}_{2}$ injection ceased and the well pressure was the largest.

The circle outlining the area where $\Delta \mathrm{P}>0.1 \mathrm{MPa}$ has an area of about $2,400 \mathrm{~km}^{2}$, which is about 140 times the plume area based on VIMPA shown in Figure 7. The pressure-affected area can potentially be an area of risk for upward brine leakage. Vertically, the impact of the pressure is generally confined within the reservoir (Figure 11a) because the rock below the reservoir is nearly impermeable and the confining zone above is thick and has very low permeability (see Figure 2). The areal $\Delta \mathrm{P}$ contour lines 50 years post-injection ( $t=70$ years) are shown in Figure 11b. Consistent with the decreasing well pressures shown in Figure 10, the simulated $\Delta \mathrm{P}$ values are much reduced compared to those at the end the injection period. However, the area where $\Delta \mathrm{P}$ $>0.1 \mathrm{MPa}$ has grown to be $\sim 3,800 \mathrm{~km}^{2}$, which is approximately 200 times the plume area based on $\mathrm{scCO}_{2}$ saturation. 


\subsection{Local Sensitivity Analysis}

\subsection{1 $\mathrm{CO}_{2}$ Injectivity}

With the assumed uncertainties in inputs (Tables 5 and 6), there is an overall absolute composite sensitivity of $31.6 \%$ on the injectivity, meaning that, in the worst case scenario (no cancellation of impacts on output), the uncertainty in $\mathrm{CO}_{2}$ injectivity is $31.6 \%$. The local sensitivity coefficients for the top 15 most sensitive inputs are shown in Figure 12. Among the 348 inputs, about $1 / 2$ of the uncertainty in $\mathrm{CO}_{2}$ injectivity was attributed to the top 4 inputs, i.e., horizontal permeability of the injection layer (MtSimon11), fracture-pressure gradient, residual saturation of the injection layer, and initial pressure of the system. About $3 / 4$ of the uncertainty was due to the top 15 inputs. It is understandable that the horizontal permeability of the injection layer directly affects the mobility of fluid in the injection zone. It is not surprising that the fracture pressure gradient has nearly the same sensitivity as the horizontal permeability of the MtSimon11 layer because this parameter controls the maximum injection rate and a larger fracture pressure would allow a higher injection rate. However, it is unexpected that the residual saturation of the injection zone was the third most sensitivity parameter because it has a relatively small impact on the mobility of either the aqueous or non-aqueous phase. Nevertheless, the residual saturation of MtSimon 11 affects the total pore volume for the transport of the liquids, a larger value meaning less available pore space for the transport of brine and $\mathrm{CO}_{2}$ and hence a reduced injectivity. It is noted that some of the residual water near the injection well is expected to be evaporated during the $\mathrm{CO}_{2}$ injection process but the dry-out zone is expected to be very small and reside near the injection wells (Zhang et al., 2016). It is of interest to note that six (except the temperature gradient) out of the seven initial condition inputs (Table 6) were among the top 15 . This result is not unexpected because the initial conditions affect the properties of the fluids and the rock.

The absolute composite sensitivities to input types (Figure 13a) indicate that three input types, i.e., the initial conditions, horizontal permeability, and residual aqueous saturation, cause more than $3 / 4$ of the uncertainty for injectivity. Often a large effort is made to characterize the injection zone and to measure the hydraulic properties (e.g., by field tests and core measurement in the laboratory), but less attention is paid to the initial conditions. The high sensitivity of $\mathrm{CO}_{2}$ 
injectivity to the initial conditions suggests considerable effort must be made to measure the reservoir conditions prior to $\mathrm{CO}_{2}$ injection. The absolute composite sensitivities for rock layers (Fig. 13b, initial conditions were excluded) indicate that nearly half of the uncertainty in injectivity was due to the properties of the MtSimon11, which is the injection layer. Among the rest of the layers, the injectivity is relatively more sensitive to the properties of the layers in the injection zone (from MtSimon1 to Lombard1_4; Table 4) than those in the confining zone. This suggests that it is critical to accurately characterize the properties and the extent of the injection zone.

\subsection{2 $\mathrm{CO}_{2}$ Plume Area}

With the assumed uncertainties in inputs (Tables 5 and 6), there is an overall absolute composite sensitivity of $25.5 \%$ on the plume area, meaning that, in the worst case scenario (no cancellation of impacts on output), the uncertainty in plume area is $25.5 \%$. The local sensitivity coefficients for the top 15 most sensitive inputs are shown in Figure 14. About 1/3 of the uncertainty in plume area was due to the top five inputs. The three most-sensitive inputs are the residual saturations of MtSimon 12 and MS13, and the horizontal hydraulic conductivity of MtSimon 11. When the residual saturation of the MtSimon 12 or 13 layers (which are right above the injection layer MtSimon 11) becomes larger, there would be less pore space for $\mathrm{CO}_{2}$ and hence a larger $\mathrm{CO}_{2}$ plume would develop. As the permeability of MtSimon 11 in the horizontal direction becomes larger, $\mathrm{CO}_{2}$ would transport faster laterally, producing a larger plume area. The porosity of MtSimon 11 has a negative sensitivity because an increased pore space would lead to a smaller plume. Interestingly, the residual saturation of MtSimon 11 also has a negative sensitivity. The reason may be that evaporation of the residual water near the injection wells in MtSimon 11 would potentially trap more $\mathrm{CO}_{2}$ in the pores initially occupied by residual water and hence a smaller plume. In total, about $2 / 3$ of the uncertainty in plume area was due to 15 of the inputs.

The absolute composite sensitivities of plume area to the 12 types of inputs are shown in Figure $15 \mathrm{a}$. The residual water saturation result in nearly $25 \%$ of the uncertainty in plume area, while the horizontal permeability, porosity, initial conditions, and vertical permeability result in about $55 \%$ of the uncertainty, and the rest of the inputs contribute to the remaining uncertainty. The large sensitivity of the residual water saturation occurs because it affects the total available 
pore space in the injection zone and hence the total volume of the smallest pores that can trap $\mathrm{CO}_{2}$. Thus, it is important to characterize the residual water saturation accurately and handle that parameter appropriately. Most models assume the relative permeability to be zero for $S_{\mathrm{w}} \leq S_{\mathrm{rw}}$. Zhang et al. (2016) presented a relative permeability model for multiphase flow for oven-dry to full saturation conditions. This model treats the residual water to be mobile and appears to simulate $\mathrm{CO}_{2}$ injection and the subsequent processes (e.g., the dry-out of brine and salt precipitation) more accurately than the classical models.

The absolute composite sensitivities to the properties of the 31 layers (initial conditions were excluded) are shown in Figure 15b. The properties of MtSimon 11, 12 and 13 contribute to about $2 / 3$ of the sensitivity because the $\mathrm{CO}_{2}$ is injected into MtSimon 11 through four lateral wells and MtSimon 12 and 13 are adjacent to and above MtSimon 11. The layers adjacent to but below MtSimon 11 (i.e., MtSimon 9 and 10) have much smaller sensitivity because, compared with MtSimon 12 and 13, much less $\mathrm{CO}_{2}$ enters into these layers during injection and post-injection. As expected, the properties of the confining zone have little impact on the plume area because $\mathrm{CO}_{2}$ does not enter this zone.

\section{Summary}

An overview is presented of the simulation that was conducted as part of a recent Class VI permit application (Gilemore et al., 2016) under the Underground Injection Control Program of the U.S. Environmental Protection Agency. Furthermore, a local sensitivity analysis was completed for injectivity and relative plume size.

The predicted structural trapping indicated that each of the multiple reservoir layers with low permeability traps a fraction of the $\mathrm{scCO}_{2}$ beneath it. Most of the injected $\mathrm{scCO}_{2}$ has not reached the top of the reservoir by the end of the simulation ( $t=500$ years) and no penetration into the overlying Upper Lombard formation caprock is predicted. Hence, the injected $\mathrm{scCO}_{2}$ is considered to be safely trapped by the stratified structure within the reservoir. The simulation results were also analyzed for mass distributions using the vertically integrated mass per area approach described by Zhang et al. (2015). The mass distribution analysis confirms that the $\mathrm{scCO}_{2}$ plume size does not change considerably after injection. 
The well pressure asymptotically approaches a maximum during the injection period and decreases rapidly toward the initial pressure after injection ceases. The spatial extent impacted by pressure build-up is much larger than the footprint of the $\mathrm{scCO}_{2}$ plume. The area corresponding to a $\Delta \mathrm{P}$ of $0.1 \mathrm{MPa}$ has an area approximately 140 and 200 times the plume area immediately after injection and 50 years post-injection, respectively. Vertically, the pressure impact is confined within the injection zone. The predictions of plume area and $\Delta \mathrm{P}$ propagation allow for Area of Review (AoR) delineation based on either one or even a tiered approach as proposed by Birkholzer et al. (2014) where areas within the extent of the plume would have higher regulatory standards than areas affected only by limited pressure changes. Overall, the simulation results indicate that the injectivity of the Mt. Simon sandstone at the FutureGen 2.0 site would be sufficient to sequester the intended $\mathrm{scCO}_{2}$ mass.

The local-sensitivity approach is capable of efficiently identifying the inputs that most influence the model prediction of $\mathrm{CO}_{2}$ injectivity and plume size, particularly when the total number of inputs is large (e.g., 10s or 100s), therefore making the use of a global approach impractical. This approach is useful for ranking model inputs, and results are useful for costeffective site characterization, injection well design, AoR uncertainty estimation, and monitoring network design. We propose a method to calculate the local sensitivity coefficient, defined as the response of the output in percent to the change of an input. According to the first-order expansion of the Taylor series over multiple variables, the local sensitivity coefficients for the various parameters are additive so that the composite sensitivity of a certain input or of a subzone can be calculated, assuming that the parameters are independent. The coefficients can also be rescaled to estimate the uncertainty of predictions for an uncertainty value that is different from those listed in Tables 5 and 6, removing the need to rerun the simulation.

Application of this approach to the FutureGen site shows that the sensitivity of $\mathrm{CO}_{2}$ injectivity to model inputs varied considerably. For $\mathrm{CO}_{2}$ injectivity, about half of the uncertainty is due to only four of the 348 inputs and 3/4 of the uncertainty is due to about 15 of the inputs; for the plume area, about $1 / 3$ of the uncertainty in plume area was due to the top five inputs. The initial conditions and the hydraulic properties of the injection layer (MtSimon 11) and its neighboring layers directly above (MtSimon 12 and 13) contribute to most of the sensitivity. This suggests that, during site characterization, substantial effort should be directed at properly quantifying these most sensitive parameters. However, the results also show that the parameters 
that are important for controlling $\mathrm{CO}_{2}$ injectivity are not the same as those for controlling the plume size. The three most sensitive inputs for injectivity were the horizontal permeability and the residual water saturation of MtSimon 11 (the injection layer), and the initial fracture-pressure gradient. For the plume area the most sensitive inputs are the residual water saturation of MtSimon 12 and 13 and the horizontal permeability of MtSimon 11. The observation that horizontal permeability is a sensitive input for both injectivity and plume size suggests that selection of a storage site is primarily a hydraulic problem, impacting the characterization phase of the site development. The approach presented here can be used for determining the sensitivity for other outputs (e.g., pressure in the confining zone), at other times (e.g., 5, 10, or $15 \mathrm{yr}$ ), and at other locations (e.g., monitoring locations), to determine which model parameters are sensitive to selected outcomes.

\section{Acknowledgements}

Funding for this research was provided by the FutureGen 2.0 program, implemented under Cooperative Agreement DE-FE0001882 between the U.S. Department of Energy and the FutureGen Industrial Alliance, a non-profit membership organization created to benefit the public interest and the interests of science through research, development, and demonstration of near-zero emissions coal technology. For more information on FutureGen 2.0, please visit www.futuregenalliance.org. Pacific Northwest National Laboratory is operated by the Battelle Memorial Institute for the Department of Energy (DOE) under Contract DE-AC06-76RLO 1830.

\section{References}

Bachu, S., Gunter, W.D., Perkins, E.H. 1994. Aquifer disposal of $\mathrm{CO}_{2}$ : hydrodynamic and mineral trapping. Energy Convers. Manag. 35:269-279.

Bacon, D.H., Ramanathan, R., Schaef, H.T., McGrail, B.P., 2014. Simulating geologic cosequestration of carbon dioxide and hydrogen sulfide in a basalt formation. Int. J. of Greenhouse Gas Control 21:165-176.

Bandilla, K.W., Celia, M.A., Elliot, T.R., Person, M., Ellet, K.M., Rupp, J.A., Gable, C., and Zhang, Y. 2012. Modeling carbon sequestration in the Illinois Basin using a vertically-integrated approach. Computing and Visualization in Science 15:39-51. 
Benisch, K., Bauer, S. 2013. Short- and long-term regional pressure build-up during $\mathrm{CO}_{2}$ injection and its applicability for site monitoring. Int. J. of Greenhouse Gas Control 19:220-233.

Birkholzer, J., Cihan, A., and Bandilla, K. 2014. A tiered area-of-review framework for geologic carbon sequestration. Greenhouse Gasses: Science and Technology 4:20:35.

Birkholzer, J.T., Zhou, Q., Cortis, A., and Finsterle, A. 2011. A sensitivity study on regional pressure buildup from large-scale $\mathrm{CO}_{2}$ storage projects. 10th International Conference on Greenhouse Gas Control Technologies, 4:4371-4378. doi: 10.1016/j.egypro.2011.02.389.

Birkholzer, J.T., Zhou, Q., and Tsang, C.F. 2009. Large-scale impact of $\mathrm{CO}_{2}$ storage in deep saline aquifers: A sensitivity study on pressure response in stratified systems. Int. J. of Greenhouse Gas Control, 3(2):181-194. doi: 10.1016/j.ijggc.2008.08.002.

Brooks, R.H., Corey, A.T. 1964. Hydraulic properties of porous media. Hydrology Papers 3 Fort Collins, Colorado: Colorado State University.

Burdine, N. T. 1953. Relative permeability calculations from pore size distribution data. Transactions of the American Institute of Mining and Metallurgical Engineers 198, 71-78.

Cameron, D.A., and Durlofsky, L.J. 2012. Optimization of well placement, $\mathrm{CO}_{2}$ injection rates, and brine cycling for geological carbon sequestration. Int. J. of Greenhouse Gas Control 10, 100-112.

Castilloa, E., Hadib, A.S., Conejoc, A., Fernández-Cantelid, A., 2004. A general method for local sensitivity analysis with application to regression models and other optimization problems. Technometrics 46, 430-444.

Cavanagh, A. 2013. Benchmark calibration and prediction of the Sleipner $\mathrm{CO}_{2}$ plume from 2006 to 2012. Energy Procedia, 37:3529-3545. doi:10.1016/j.egypro.2013.06.246.

Cavanagh, A. and B. Nazarian. 2014. A new and extended Sleipner benchmark model for $\mathrm{CO}_{2}$ storage simulations in the Utsira Formation. Energy Procedia, 63:2831-2835. doi:10.1016/j.egypro.2014.11.305.

Chadwick, R.A., Williams, G.A., Williams, J.D.O., Noy, D.J. 2012. Measuring pressure performance of a large saline aquifer during industrial-scale $\mathrm{CO}_{2}$ injection: The Utsira Sand, Norwegian North Sea. Int. J. of Greenhouse Gas Control 10: 374-388.

Cihan, A., Birkholzer, J.T., and Zhou, Q.L. 2013. Pressure buildup and brine migration during $\mathrm{CO}_{2}$ storage in multilayered aquifers. Ground Water, 51(2):252-267. doi: 10.1111/j.17456584.2012.00972.x.

Corey, A.T. 1954. The interrelation between gas and oil permeabilities. Producer's Monthly 19(1), 38-42. 
Court, B., Bandilla, K.W., Celia, M.A., Janzen. A., Dobossy, M., Nordbotten, J.M. 2012. Applicability of vertical-equilibrium and sharp-interface assumptions in $\mathrm{CO}_{2}$ sequestration modeling. Int. J. Greenhouse Gas Control 10: 134-147.

Deflandre, J.P., A. Estublier, A. Baroni, J.M. Daniel, and F. Adjemian. 2011. In Salah $\mathrm{CO}_{2}$ injection modeling: A preliminary approach to predict short term reservoir behavior. Energy Procedia, 4:3574-3581. doi:10.1016/j.egypro.2011.02.286.

Doughty, C. 2007. Modeling geologic storage of carbon dioxide: Comparison of non-hysteretic and hysteretic characteristic curves. Energy Convers. and Management 48 (6), 1768-1781.

Doughty, C., Freifeld, B.M., and Trautz, R.C. 2008. Site characterization for $\mathrm{CO}_{2}$ geologic storage and vice versa: the Frio brine pilot, USA as a test case. Environ. Geol. 54, 1635-1656.

Doughty, C. 2010. Investigation of $\mathrm{CO}_{2}$ plume behavior for a large-scale pilot test of geologic carbon storage in a saline formation. Transport in Porous Media 82 (1), 49-76.

Durucan, S., J.Q. Shi, C. Sinayuc, and A. Korre. 2011. In Salah $\mathrm{CO}_{2}$ storage jip: Carbon dioxide plume extension around Kb-502 well - New insights into reservoir behavior at the In Salah storage site. Energy Procedia, 4:3379-3385. doi:10.1016/j.egypro.2011.02.260.

Dutta, P., Zoback, M.D. 2012. $\mathrm{CO}_{2}$ sequestration into the Wyodak coal seam of Powder River Basin - Preliminary reservoir characterization and simulation. Int. J. of Greenhouse Gas Control 9: 103-116.

Foglia, L., Hill, M.C., Mehl, S.W., Burlando, P., 2009. Sensitivity analysis, calibration, and testing of a distributed hydrological model using error-based weighting and one objective function. Water Resources Research 45, W06427.

Gilmore, T., Bonneville, A., Sullivan, C., Kelley, M., Appriou, D., Vermeul, V., White, S., Zhang, F., Bjornstad, B., Cornet, F., Gerst, J., Gupta, N., Hund, G., Horner, J., Last, G., Lanigan, D., Oostrom, M., McNeil, C., Moody, M., Rockhold, M., Elliott, M., Spane F., Strickland, C., Swartz, L., Thorne, P., Brown, C., Hoffmann J., and Humphreys, K. 2016. Characterization and design of the FutureGen 2.0 carbon storage site. Int. J. Greenhouse Gas Control 53: 1-10.

Giorgis, T., Carpita, M., Battistelli, A. 2007. 2D modeling of salt precipitation during the injection of dry $\mathrm{CO}_{2}$ in a depleted gas reservoir. Energy Convers.and Management 48 (6), 18161826.

Han, W.S., Kim, K.-Y., Esser, R.P., Park, E., McPherson, B.J., 2011. Sensitivity study of simulation parameters controlling $\mathrm{CO}_{2}$ trapping mechanisms in saline formations. Transport in Porous Media 90, 807-829.

Huang, X., Bandilla, K.W., Celia, M.A., Bachu, S. 2014. Basin-scale modeling of CO2 storage using models of varying complexity. Int. J. of Greenhouse Gas Control 20: 73.86. 
Kim, K-Y., Han, W.S., Oh, J., Kim, T., Kim J-C. 2012. Characteristics of salt-precipitation and the associated pressure build-up during CO2 storage in saline aquifers. Transport in Porous Media 92, 397-418.

Land, C.S. 1968. Calculation of imbibition relative permeability for two and three-phase flow from rock properties. Soc. Pet. Eng. J. 8: 149-156.

Liu, F., Peng, L., Zhu, C., Xiao, Y. 2011. Coupled reactive flow and transport modeling of $\mathrm{CO}_{2}$ sequestration in the Mt. Simon sandstone formation, Midwest, U.S.A. Int. J. of Greenhouse Gas Control 5, 294-307.

Mathias, S.A., Gluyas, J.G., Gonzalez Martinez de Miguel, G.J., Bryant, S.L., Wilson, D. 2013. On relative permeability uncertainty and $\mathrm{CO}_{2}$ injectivity estimation for brine aquifers. Int. J. of Greenhouse Gas Control 12, 200-212.

Mathias, S.A., Gluyas, J.G., De Miguel, G.J.G.M. and Hosseini, S.A. 2011a. Role of partial miscibility on pressure buildup due to constant rate injection of $\mathrm{CO}_{2}$ into closed and open brine aquifers. Water Resources Research, 47. doi: 10.1029/2011wr011051.

Mathias, S.A., De Miguel, G.J.G.M., Thatcher, K.E., and Zimmerman, R.W. 2011b. Pressure buildup during $\mathrm{CO}_{2}$ injection into a closed brine aquifer. Transport in Porous Media, 89(3):383397. doi: 10.1007/s11242-011-9776-z.

McKay, M.D., Beckman, R.J., Conover, W.J., 1979. A comparison of three methods for selecting values of input variables in the analysis of output from a computercode. Technometrics 21, 239-245.

Middleton, R.S., Keating, G.N., Stauffer, P.H., Jordan, A.B., Viswanathan, H.S., Kang, Q.J., Carey, J.W., Mulkey, M.L., Sullivan, E.J., Chu, S.P., Esposito, R., Meckel, T.A. 2012. The cross-scale science of $\mathrm{CO}_{2}$ capture and storage: from pore scale to regional scale. Energy Environmental Science 5, 7328-7345.

Mitiku, A.B., Bauer, S. 2013. Optimal use of a dome-shaped anticline structure for $\mathrm{CO}_{2}$ storage: a case study in the North German sedimentary basin. Environ. Earth Sciences 70 (8), 3661-3673.

Nicot, J.-P. 2008. Evaluation of large-scale $\mathrm{CO}_{2}$ storage on fresh-water sections of aquifers: an example from the Texas Gulf Coast Basin. Int. J. of Greenhouse Gas Control 2: 583-593.

Okwen, R., Stewart, M. and Cunningham, J. 2011. Effect of well orientation (vertical Vs. horizontal) and well length on the injection of $\mathrm{CO}_{2}$ in deep saline aquifers. Transport in Porous Media, 90(1):219-232. doi: 10.1007/s11242-010-9686-5.

Oostrom, M., Lenhard, R.J., van Geel, P., White, M.D., Wietsma, T.W. 2005. Comparison of models describing residual NAPL formation in the vadose zone. Vadose Zone J. 4:163-174. 
Person, M., Banerjee, A. Rupp, J., Medina, C., Lichtner, P., Gable, C., Pawar R., Celia, M., McIntosh, J., Bense, V. 2010. Assessment of basin-scale hydrologic impacts of $\mathrm{CO}_{2}$ sequestration, Illinois Basin. Int. J. Greenhouse Gas Control 4: 840-854.

Pham, V., Riis, T.H., Gjeldvik, F., Halland, I.T., Tappel, E.K., Aagaard, P. 2013. Assessment of $\mathrm{CO}_{2}$ injection into the south Utsira-Skade aquifer, the North Sea, Norway. Energy 55, 529-540.

Peaceman, D.W. 1983. Interpretation of well-block pressures in numerical reservoir simulation with nonsquare grid blocks and anisotropic permeability. Society of Petroleum Engineers of AIME 23, 531-543.

Peaceman, D.W.1990. Interpretation of wellblock pressures in numerical reservoir simulation: Part 3 - Off-center and multiple wells within a wellblock. SPE Reservoir Engineering 5, 227232.

Pruess, K., Garcia, J. 2002. Multiphase flow dynamics during $\mathrm{CO}_{2}$ disposal into saline aquifers. Environ. Geology 42 (2-3), 282-295.

Pruess, K., Garcia, J., Kovscek, T., Oldenburg, O., Rutqvist, J., Steefel, C., and Xu, T.F. 2004. Code intercomparison builds confidence in numerical simulation models for geologic disposal of $\mathrm{CO}_{2}$. Energy, 29(9-10):1431-1444. doi:10.1016/j.energy.2004.03.077.

Pruess, K. and Nordbotten J. 2011. Numerical simulation studies of the long-term evolution of a $\mathrm{CO}_{2}$ plume in a saline aquifer with a sloping caprock. Transport in Porous Media, 90(1):135-151. doi:10.1007/s11242-011-9729-6.

Rasmussen, K., Tsang, C-F., Tsang, Y., Rasmussen, M., Pan, L., Fagerlund, F., Bensabat, J. Niemi, A. 2014. Distribution of injected $\mathrm{CO}_{2}$ in a stratified saline reservoir accounting for coupled wellbore-reservoir flow. Greenhouse Gases Science and Technology, 4:1-18.

Rossi, C. and Nimmo, J.R. 1994. Modeling of soil water retention from saturation to over dryness. Water Resour. Res., 30:701-708.

Rutqvist, J., D.W. Vasco, and L. Myer. 2010. Coupled reservoir-geomechanical analysis of $\mathrm{CO}_{2}$ injection and ground deformations at In Salah, Algeria. Int. J. of Greenhouse Gas Control, 4(2):225-230. doi:10.1016/j.ijggc.2009.10.017.

Sarkarfarshi, M., Malekzadeh, F.A., Gracie, R., Dusseault, M.B., 2014. Parametric sensitivity analysis for $\mathrm{CO}_{2}$ geosequestration. Int. J. of Greenhouse Gas Control 23, 61-71.

Senel, O., Will, R., Butsch, R.J. 2014. Integrated reservoir modeling at the Illinois Basin Decatur Project. Greenhouse Gases Science and Technology 4: 662-684.

Singh, V.P., A. Cavanagh, H. Hansen, B. Nazarian, M. Iding, and P.S. Ringrose. 2010. Reservoir modeling of $\mathrm{CO}_{2}$ plume behavior calibrated against monitoring data from Sleipner, Norway. SPE-134891-MS. Society of Petroleum Engineers. 
Sung, R-T., Li, M-H., Dong, J-J., Lin, A, T-S., Hsu, S-K, Wang, C-Y, Yang, C-N. 2014. Numerical assessment of $\mathrm{CO}_{2}$ geological sequestration in sloping and layered heterogeneous formations: A case study from Taiwan. Int. J. of Greenhouse Gas Control, 20:168-179.

Vermeul, V.R., Amonette, J.E., Strickland, C.E., Williams, M.D. Bonneville, A. 2016. An overview of the monitoring program design for the FutureGen 2.0 $\mathrm{CO}_{2}$ storage site. Int. J. Greenhouse Gas Control, 51: 193-20.

Vilarrasa, V. 2014. Impact of $\mathrm{CO}_{2}$ injection through horizontal and vertical wells on the caprock mechanical stability. Int. J. of Rock Mechanics and Mining Sciences, 66, 151-159.

USEPA. 2011. 40 CFR 146.84. Code of Federal Regulations, Title 40, Protection of Environment, Part 146. Underground Injection Control Program: Criteria and Standards. Section 84, Area of review and corrective action. EPA Office of Water, Washington, DC.

USEPA. 2013. Geologic sequestration of carbon dioxide underground injection control (UIC) Program Class VI well area of review evaluation and corrective action guidance. EPA Office of Water, Washington, DC.

Wainwright, H.M., Finsterle, S., Zhou, Q., Birkholzer, J.T., 2013. Modeling the performance of large-scale $\mathrm{CO}_{2}$ storage systems: A comparison of different sensitivity analysis methods. Int. J. of Greenhouse Gas Control 17, 189-205.

Webb, S.W. 2000. A simple extension of two-phase characteristic curves to include the dry region. Water Resour. Res., 36:1425-1430.

White, M.D., Bacon, D.H., White, S.K., and Zhang, Z.F. 2013. Fully coupled well models for fluid injection and production. Energy Procedia, 37: 3960-3970.

doi:http://dx.doi.org/10.1016/j.egypro.2013.06.295.

White, M.D., Bacon, D.H., McGrail, B.P., Watson, D.J., White, S.K., and Zhang, Z.F. 2012. STOMP Subsurface Transport over Multiple Phases: STOMP-CO2: STOMP-CO2E Guide: Version 1.0, PNNL-21268.

Yamamoto, H., Zhang, K., Karasaki, K., Marui, A., Uehara, H., and Nishikawa, N. 2009. Numerical investigation concerning the impact of $\mathrm{CO}_{2}$ geologic storage on regional groundwater flow. Int. J. of Greenhouse Gas Control 3:586-599.

Yamamoto, H. and Doughty, C. 2011. Investigation of gridding effects for numerical simulations of CO2 geologic sequestration. Int. J. of Greenhouse Gas Control 5:975-985.

Yoshida, N., Levine, J.S., Stauffer, P.H., 2016. Investigation of uncertainty in $\mathrm{CO}_{2}$ reservoir models: A sensitivity analysis of relative permeability parameter values. Int. J.of Greenhouse Gas Control 49, 161-178. 
Zhang, Z.F. 2011. Soil water retention and relative permeability for conditions from oven-dry to full saturation. Vadose Zone J. 10, 1-10.

Zhang, Z.F., White, S.K., Bonneville, A., Gilmore, T.J., 2014. Local sensitivity of predicted $\mathrm{CO}_{2}$ injectivity and plume extent to model inputs for the FutureGen 2.0 site. Energy Procedia 63, 3805-3814.

Zhang, Z.F., White, S.K., White, M.D. 2015. Delineating the horizontal plume extent and $\mathrm{CO}_{2}$ distribution at sequestration sites. Int. J. of Greenhouse Gas Control. 43, 141-148.

Zhao, H., Liao, X., Chen, Y., Zhao, X., 2010. Sensitivity analysis of $\mathrm{CO}_{2}$ sequestration in saline aquifers. Petroleum Science 7, 372-378.

Zhou, Q., and Birkholzer, J.T. 2011. On scale and magnitude of pressure build-up induced by large-scale geologic storage of $\mathrm{CO}_{2}$. Greenhouse Gases Science and Technology 1: 11-20.

Zhou, Q., Birkholzer, J.T., Mehnert, E., Lin, Y., Zhang. K. 2010. Modeling basin- and plumescale processes of $\mathrm{CO}_{2}$ storage for full-scale deployment. Ground Water 48 (4), 494-514. 


\section{Tables}

Table 1. Summary of initial conditions for Class VI permit simulation.

\begin{tabular}{lll}
\hline Parameter & Reference elevation & Value \\
\hline Reservoir Pressure & $1041 \mathrm{~m}$ & $12.34 \mathrm{MPa}$ \\
Aqueous Saturation & & 1.0 \\
Reservoir Temperature & $1001 \mathrm{~m}$ & $35.9{ }^{\circ} \mathrm{C}$ \\
Temperature Gradient & & $0.01224^{\circ} \mathrm{C} / \mathrm{m}$ \\
Salinity & & $47,500 \mathrm{ppm}$ \\
\hline
\end{tabular}

Table 2. Mass rate of $\mathrm{scCO}_{2}$ injection for each of the four lateral injection wells (Class VI permit simulation).

\begin{tabular}{ccc}
\hline & Length of & Mass Rate of \\
Injection Well \# & Lateral Leg $(\mathrm{m})$ & $\mathrm{CO}_{2}$ Injection (MMT/yr) \\
\hline 1 & 457.2 & 0.2063 \\
2 & 762.0 & 0.3541 \\
3 & 762.0 & 0.3541 \\
4 & 457.2 & 0.1856 \\
\hline
\end{tabular}

Table 3. Brooks-Corey parameters values and relation to permeability $(k)$ ranges for the Class VI permit simulation.

\begin{tabular}{cccl}
\hline$k\left(10^{-15} \mathrm{~m}^{2}\right)$ & $P_{c}^{e}\left(10^{4} \mathrm{~Pa}\right)$ & $\lambda(-)$ & $S_{l r}(-)$ \\
\hline$<40.62$ & 4.014 & 0.831 & 0.0597 \\
40.62 to 228 & 1.540 & 0.621 & 0.0810 \\
228 to 900.5 & 1.420 & 1.166 & 0.0708 \\
$>900.5$ & 0.987 & 1.353 & 0.0440 \\
\hline
\end{tabular}


Table 4. Layer configuration for sensitivity simulations.

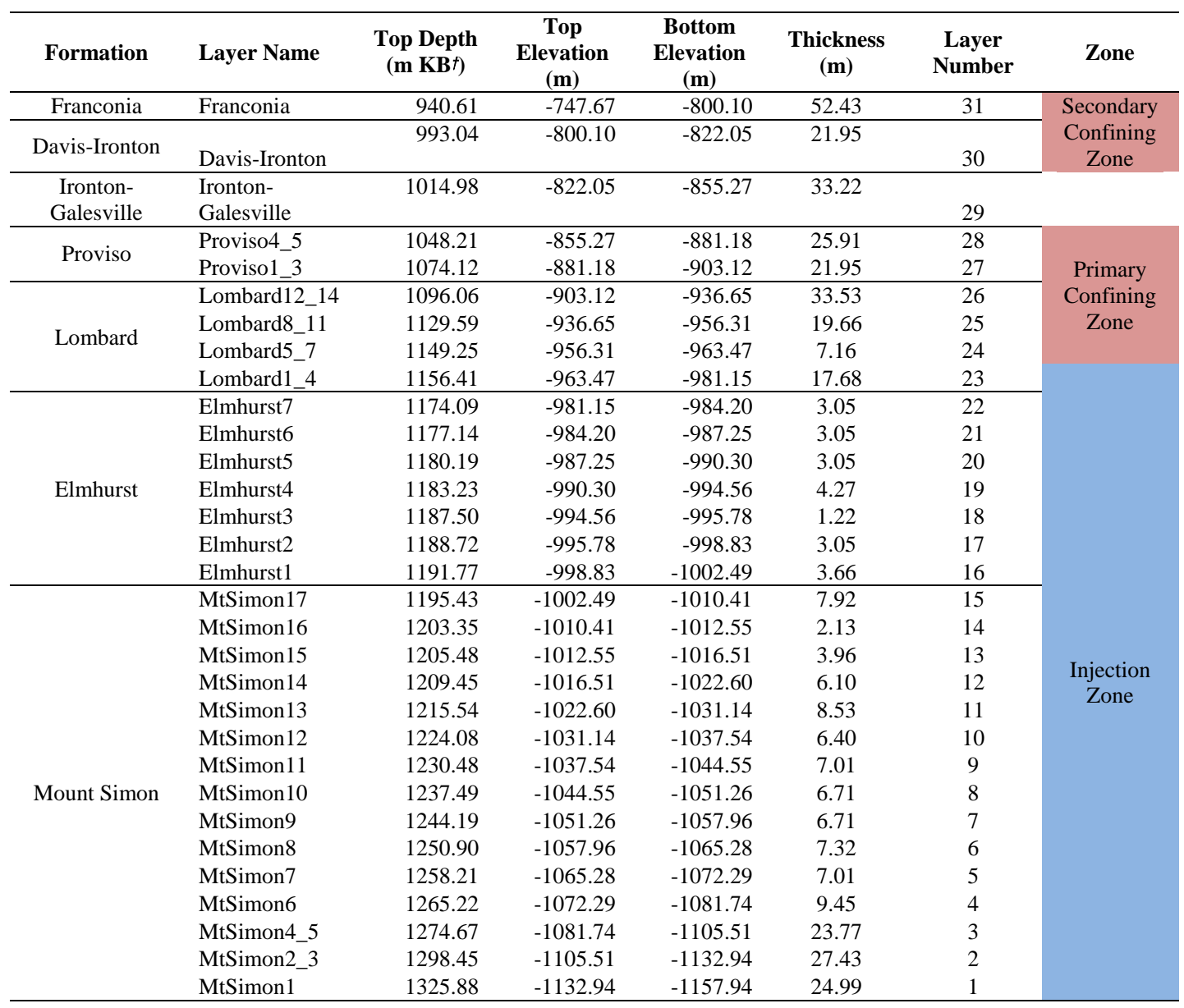


Table 5. Overview of parameter values and assumed standard deviations $\left(\sigma_{x}\right)$ in the sensitivity analysis.

\begin{tabular}{|c|c|c|c|c|c|c|}
\hline & Name & $\begin{array}{l}\text { Parameter } \\
\text { Symbol }\end{array}$ & Units & Distribution & $\begin{array}{l}\Delta X \text { for ND; } \\
b \text { for } L N D\end{array}$ & $\sigma_{x}$ \\
\hline 1 & Porosity & por & $\mathrm{m}^{3} \mathrm{~m}^{-3}$ & $\mathrm{~N}$ & 0.01 & 0.01 \\
\hline 2 & $\begin{array}{l}\text { Horizontal } \\
\text { Permeability }\end{array}$ & $\mathrm{kh}$ & $\mathrm{mD}$ & $\mathrm{LN}$ & 0.1 & 0.095 \\
\hline 3 & Vertical Permeability & $\mathrm{kv}$ & $\mathrm{mD}$ & $\mathrm{LN}$ & 0.1 & 0.095 \\
\hline 4 & Gas Entry Pressure & pe & $\mathrm{m}$ & $\mathrm{LN}$ & 0.1 & 0.095 \\
\hline 5 & $\begin{array}{l}\text { Pore Size Distribution } \\
\text { Parameter Lambda }\end{array}$ & lambda & - & $\mathrm{N}$ & 0.1 & 0.1 \\
\hline 6 & $\begin{array}{l}\text { Residual Water } \\
\text { Saturation }\end{array}$ & srw & - & $\mathrm{N}$ & 0.1 & 0.1 \\
\hline 7 & $\begin{array}{c}\text { Maximum Trapped Gas } \\
\text { Saturation }\end{array}$ & srn & - & $\mathrm{N}$ & 0.1 & 0.1 \\
\hline 8 & Particle Density & rho_g & $\mathrm{kg} \mathrm{m}^{-3}$ & $\mathrm{~N}$ & 100 & 100 \\
\hline 9 & Pore Compressibility & comp & $\mathrm{pa}^{-1}$ & $\mathrm{LN}$ & 0.1 & 0.095 \\
\hline 10 & Thermal Conductivity & $\mathrm{kt}$ & $\mathrm{W} \mathrm{m}{ }^{-1} \mathrm{~K}^{-1}$ & $\mathrm{LN}$ & 0.1 & 0.095 \\
\hline 11 & Heat Capacity & $\mathrm{cp}$ & $\mathrm{J} \mathrm{kg}^{-1} \mathrm{~K}^{-1}$ & $\mathrm{~N}$ & 100 & 100 \\
\hline
\end{tabular}

$\mathrm{N}=$ Normal; $\mathrm{LN}=$ Lognormal

Table 6. Changes in initial conditions and the assumed standard deviation for sensitivity analysis.

\begin{tabular}{cccccc}
\hline \multicolumn{3}{c}{$\begin{array}{c}\text { Parameter } \\
\text { Symbol }\end{array}$} & Units & $\Delta \mathrm{X}$ & Assumed \\
\hline 1 & Salt Fraction & $\mathrm{c}$ & - & 0.01 & $\sigma_{x}$ \\
\hline 2 & $\begin{array}{c}\text { Salinity Gradient } \\
\text { Injection Zone }\end{array}$ & $\mathrm{cg}$ & $\mathrm{m}^{-1}$ & $3.048 \times 10^{-5}$ & $3.048 \times 10^{-5}$ \\
& Pressure & $\mathrm{p}$ & $\mathrm{bar}$ & 0.6895 & 0.6895 \\
3 & Temperature & $\mathrm{t}$ & ${ }^{\circ} \mathrm{C}$ & 5.56 & 1.11 \\
4 & Temperature Gradient & $\mathrm{tg}$ & ${ }^{\circ} \mathrm{C} \mathrm{m}^{-1}$ & 0.00182 & 0.00182 \\
5 & Fracture-Pressure & & & & \\
& Gradient & $\mathrm{fg}$ & $\mathrm{bar} \mathrm{m}^{-1}$ & 0.0147 & 0.0147 \\
6 & Injection Temperature & $\mathrm{t}$ & ${ }^{\circ} \mathrm{C}$ & 2.78 & 2.78 \\
7 & & & & & \\
\hline
\end{tabular}


Figures

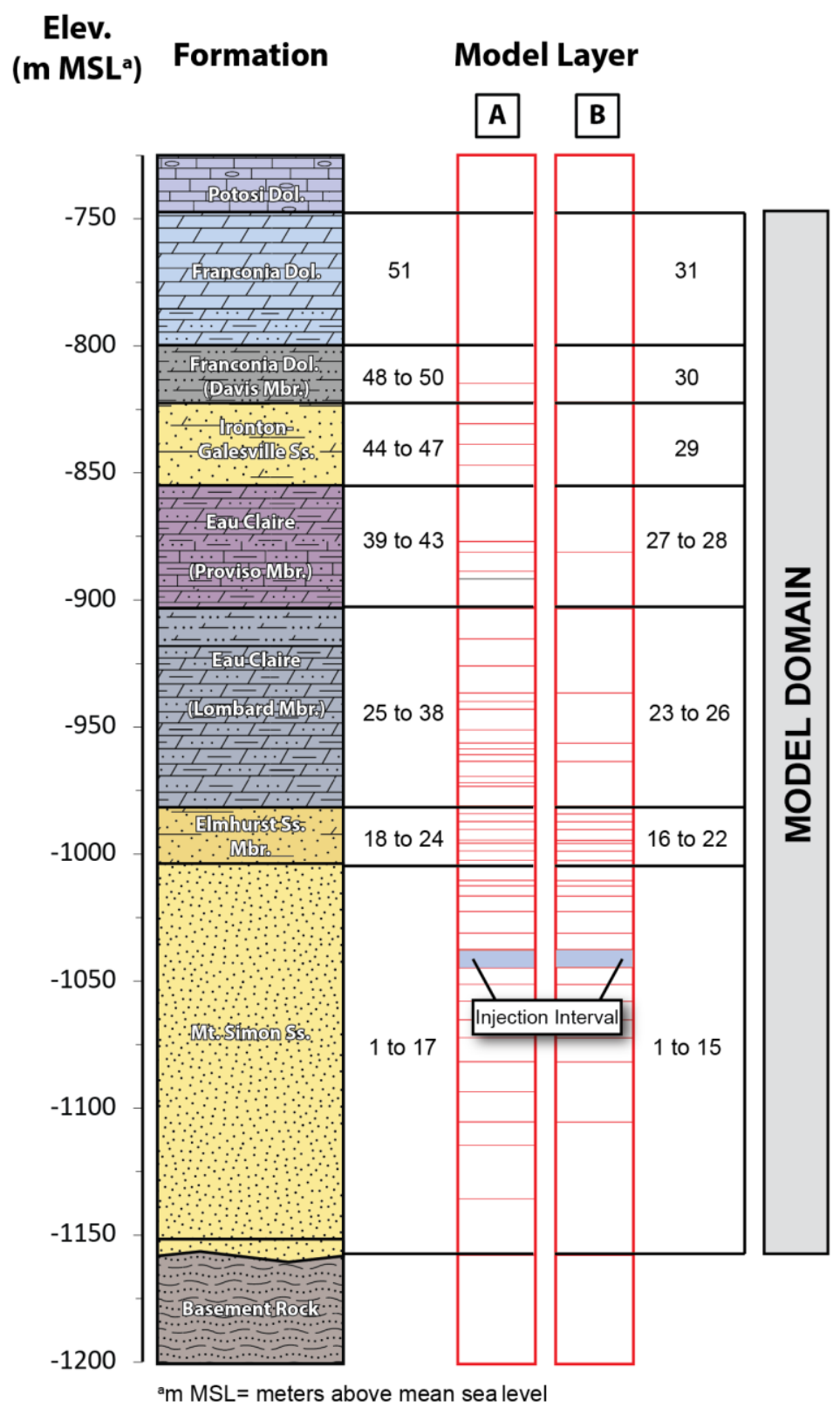

Figure 1. Overview of stratigraphy, computational model layers, and injection interval location for Class VI permit model (column A), and (b) sensitivity analysis reference case (column B) at the location of the stratigraphic well. The layer thicknesses vary spatially. 

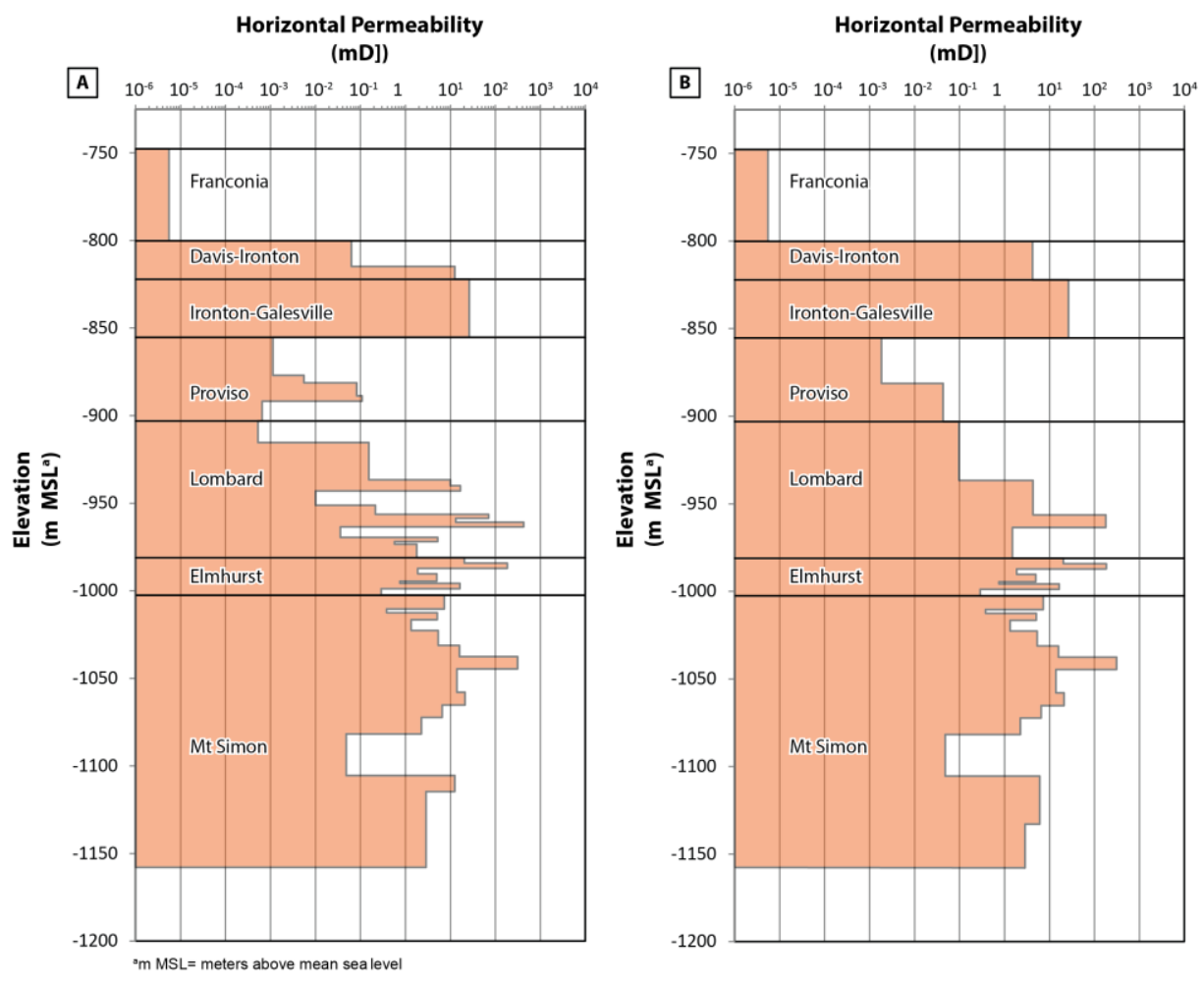

Figure 2. Horizontal permeability (in $\mathrm{mD}$ ) versus depth (shown as Elevation in m MSL) for (a) Class VI permit model, and (b) Sensitivity analysis reference case. The layer thicknesses are those at the location of the stratigraphic well and vary spatially. 

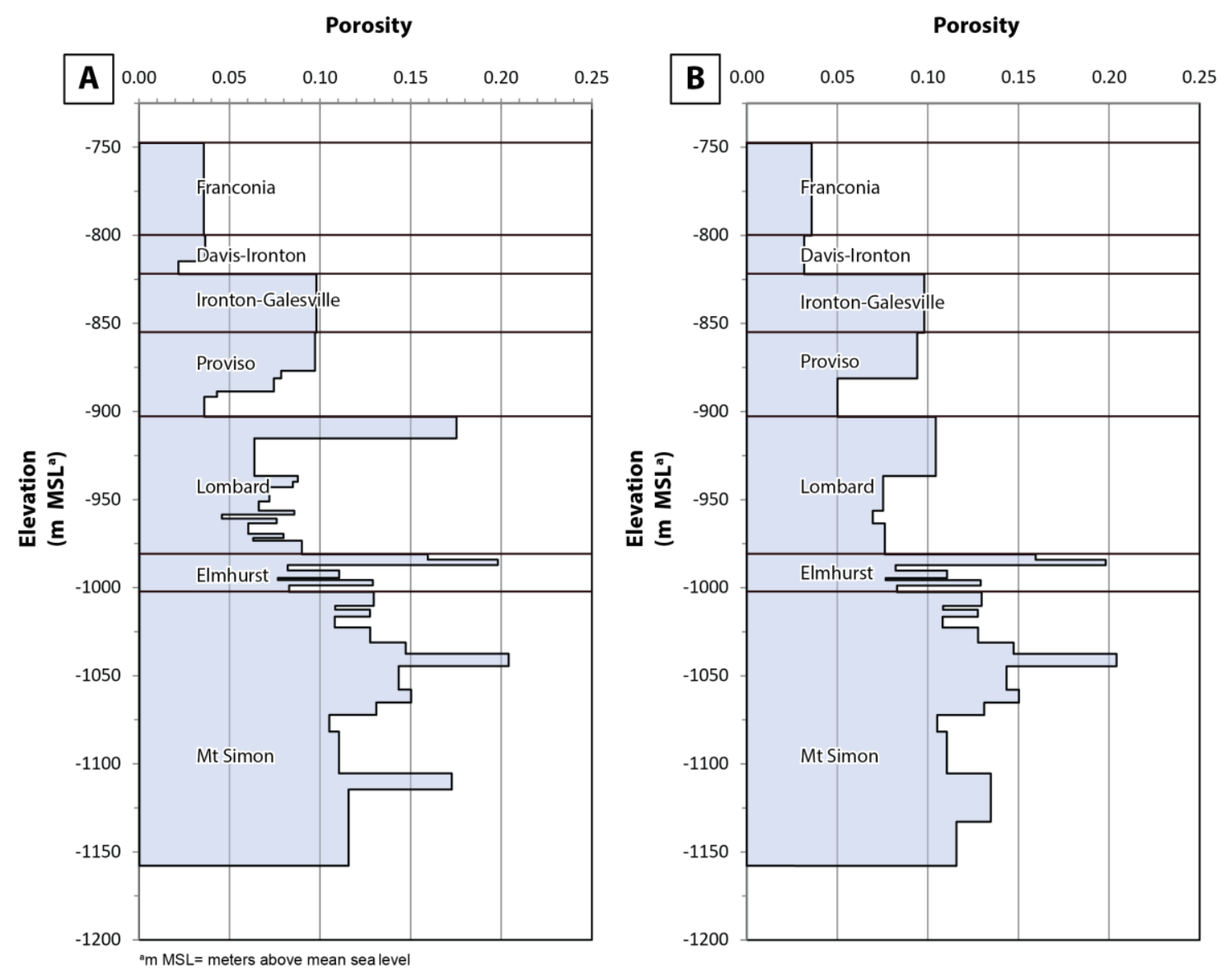

Figure 3. Porosity versus depth (shown as Elevation in m MSL) for (a) Class VI permit model, and (b) Sensitivity analysis reference case. 


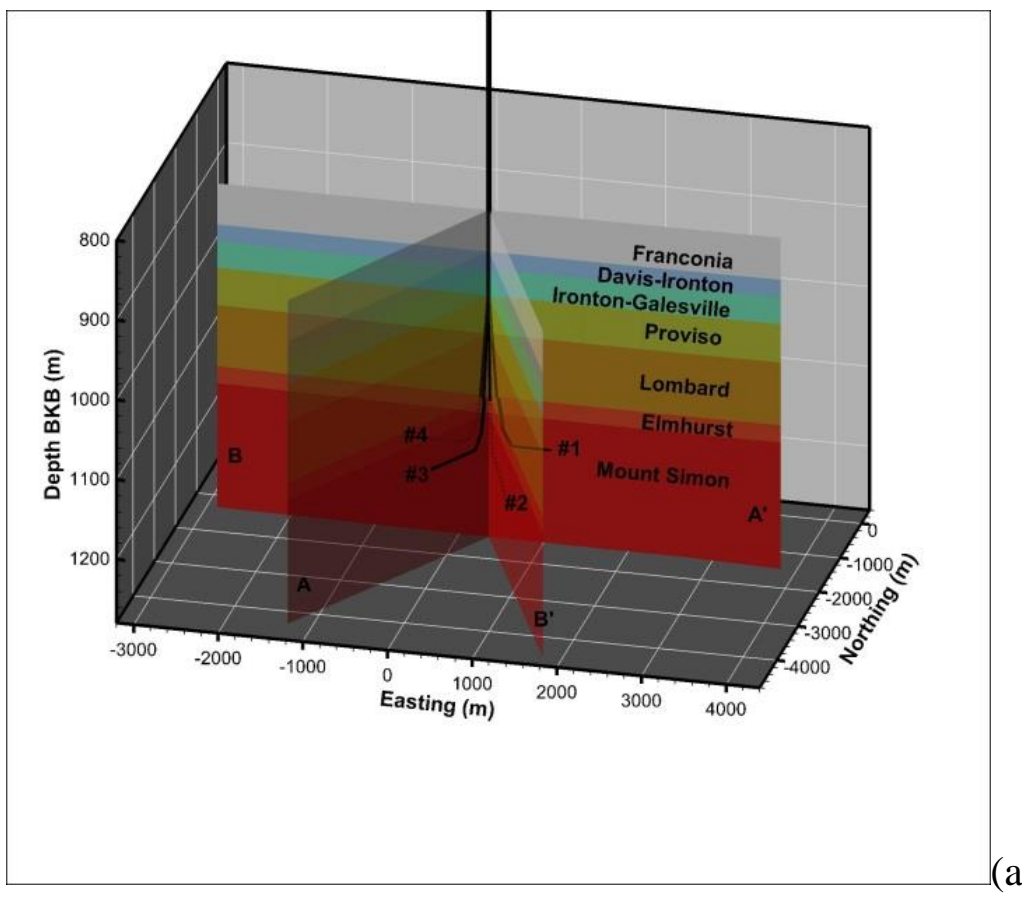

(a)

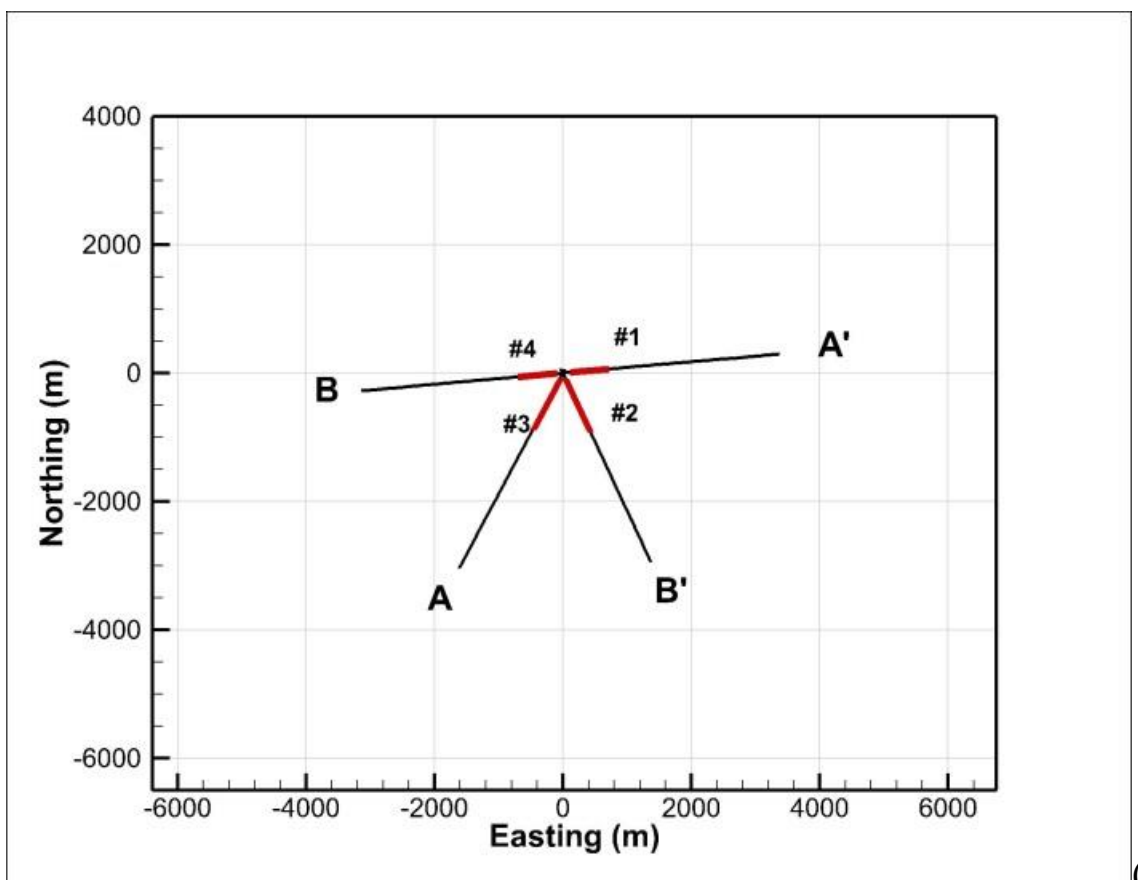

Figure 4. (a) 3-D view and (b) plan view of lateral well design. In plot b, the red lines denote the injection wells and the black lines denote cross-section A-A' and B-B'. 


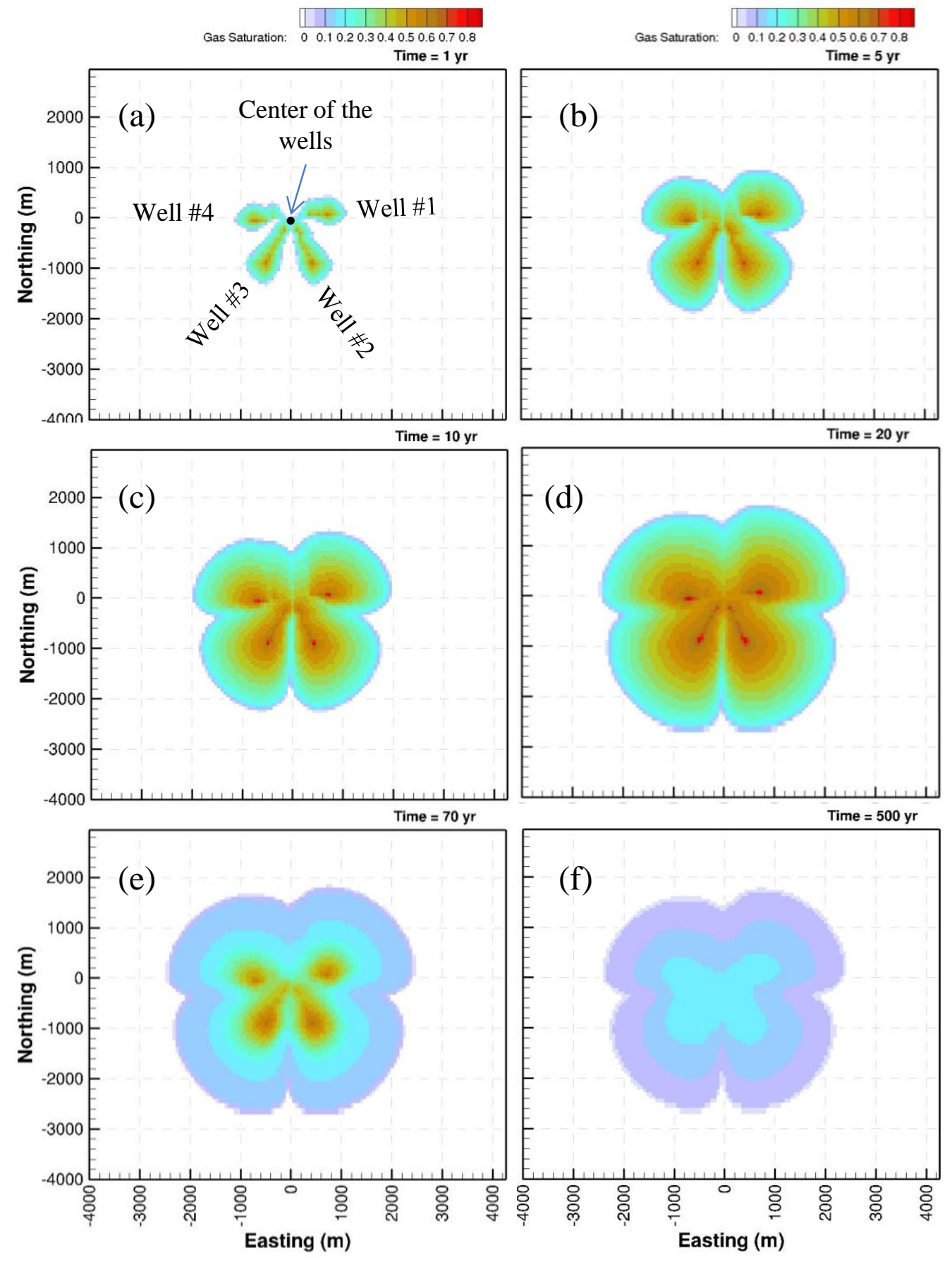

Figure 5. $\mathrm{scCO}_{2}$ saturations at various times showing the evolution of the plume in the Mount Simon layer 11 (location of lateral parts of the injection wells). 

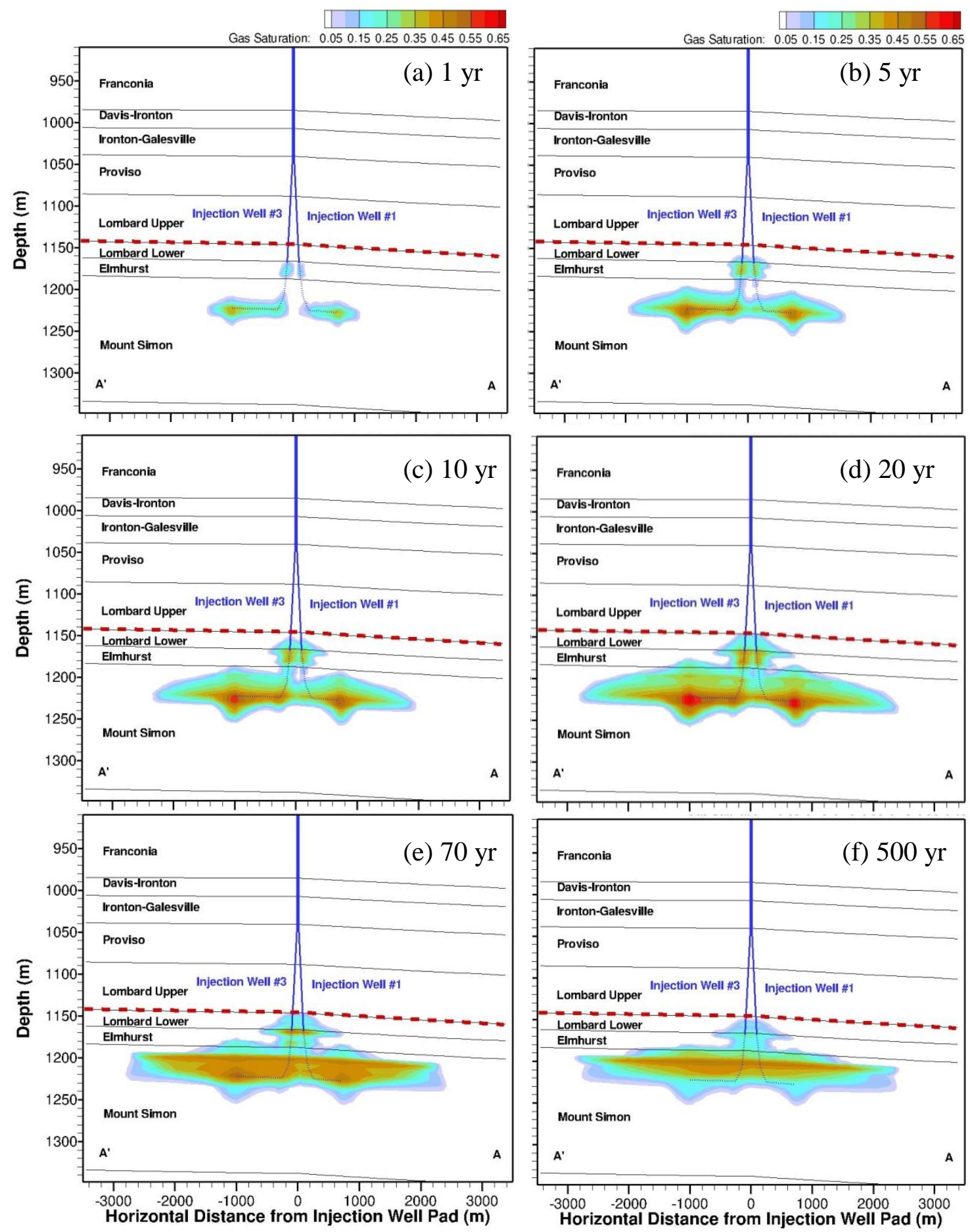

Figure 6. Cutaway view of $\mathrm{scCO}_{2}$ saturation along transect A-A' (wells \#1 and \#3) showing the evolution of the $\mathrm{scCO}_{2}$ plume. The perforated sections of the wells are shown as dashed lines inside the Mt. Simon plumes. The dashed red lines show the upper boundary of the injection zone. Depth $=187-$ Elevation. 


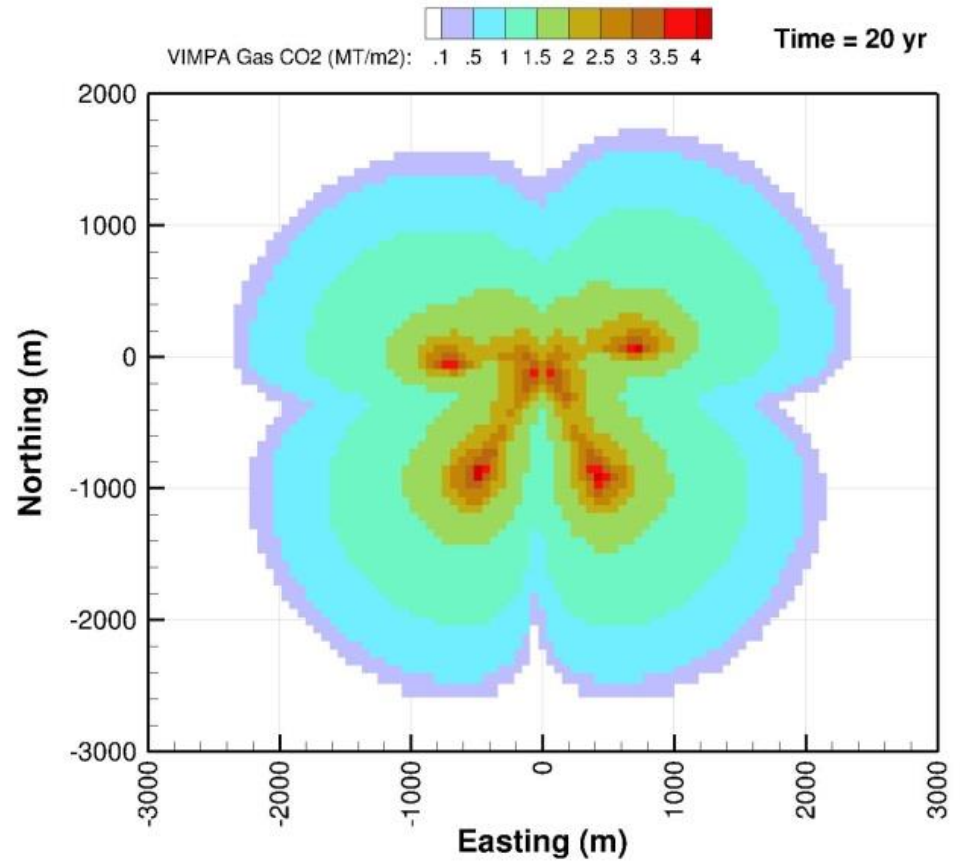

(a)

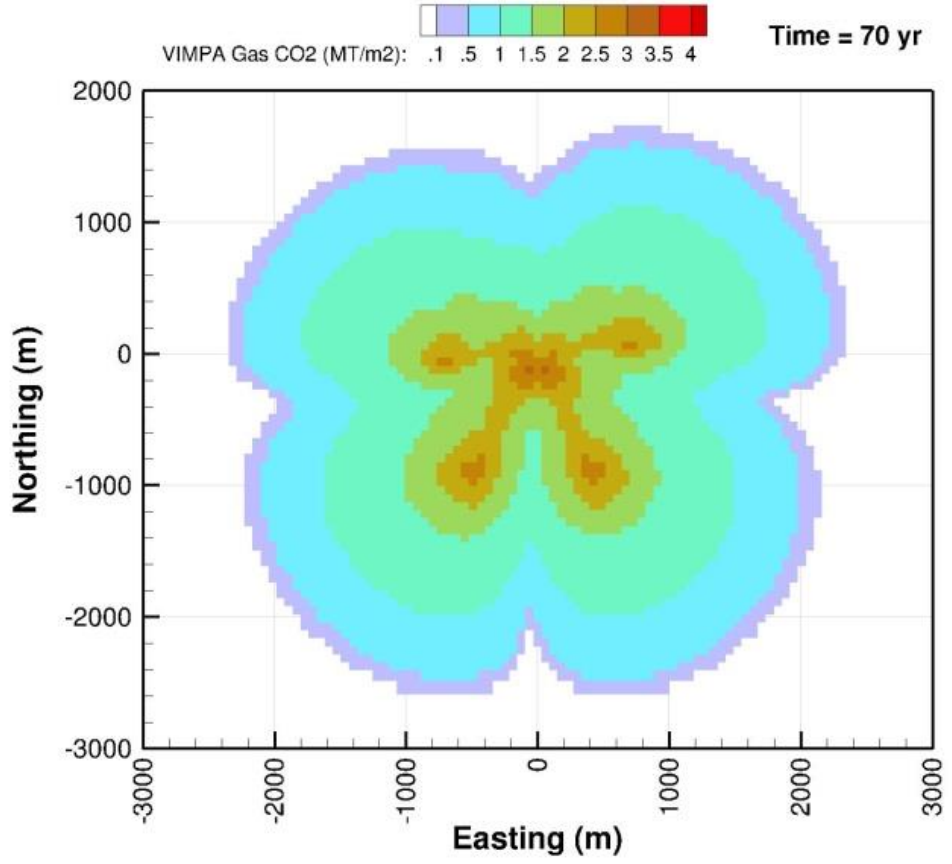

Figure 7. Horizontal $\mathrm{scCO}_{2}$ mass distribution (mass per $\mathrm{m}^{2}$ ) at (a) $t=20$ years, and (b) $t=70$ years. 


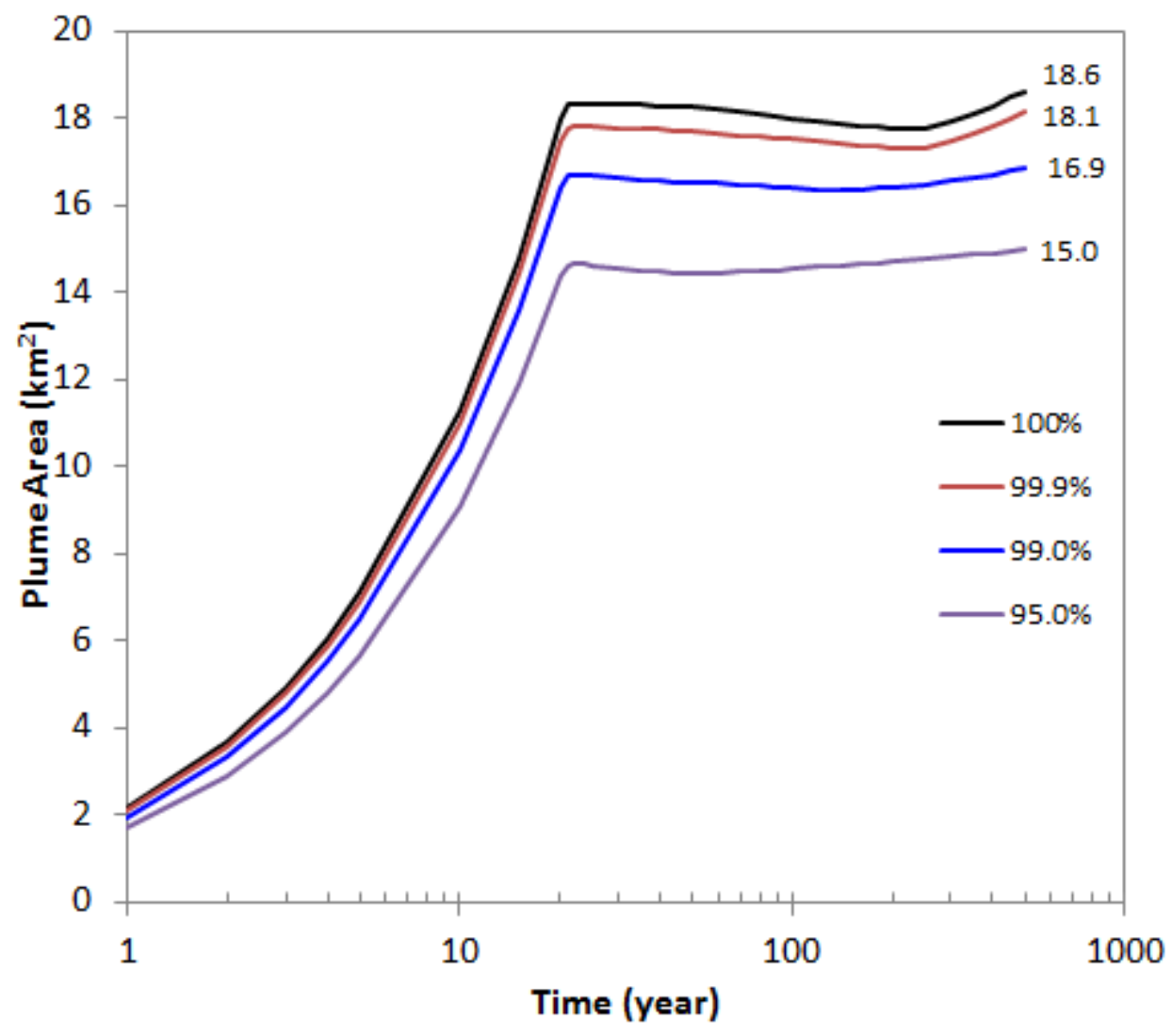

Figure 8. Plume area containing 95, 99, 99.9 and $100 \%$ of $\mathrm{scCO}_{2}$ mass. 


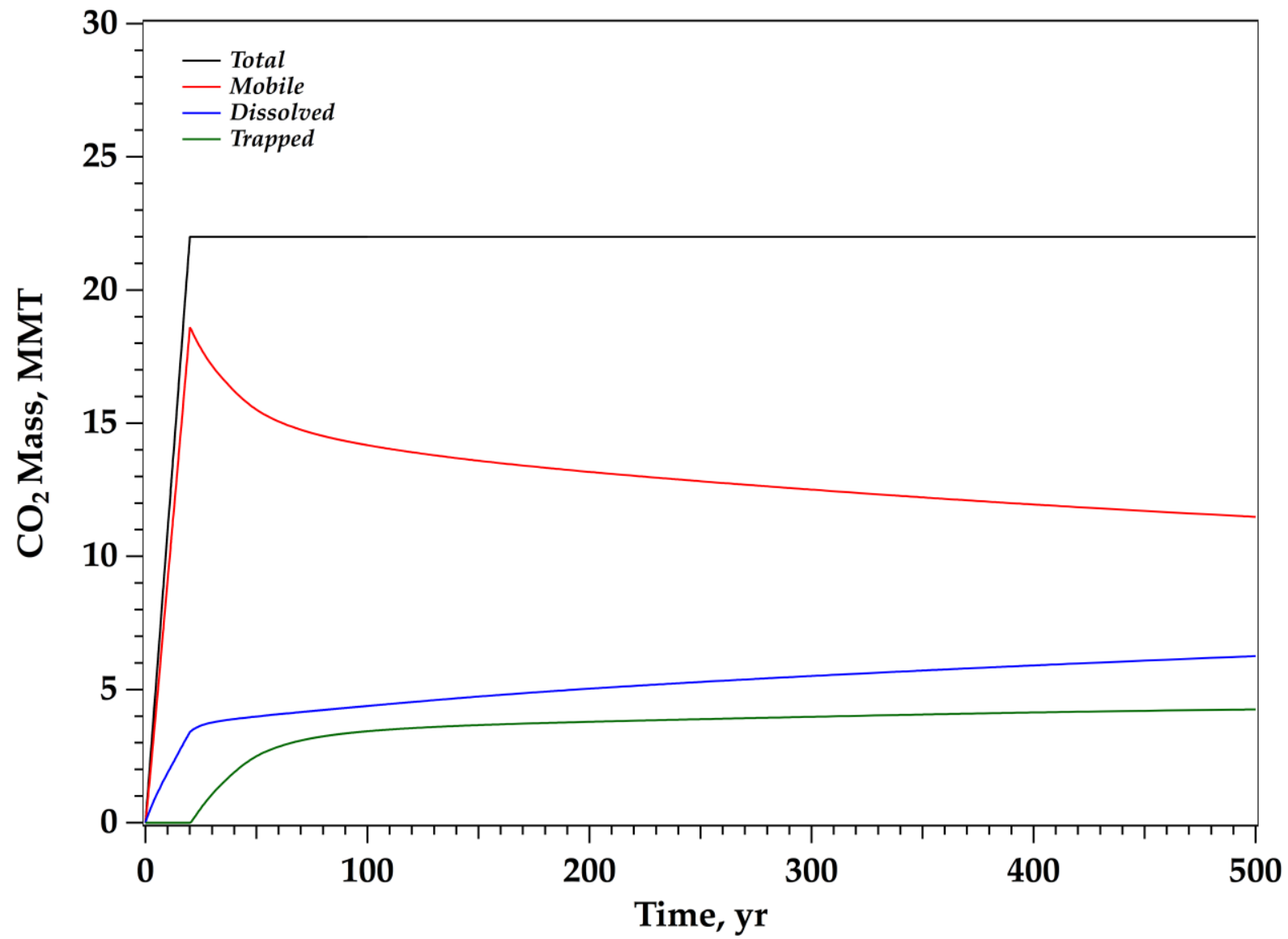

Figure 9. Mobile, trapped, and dissolved $\mathrm{scCO}_{2}$ mass distribution over time. 


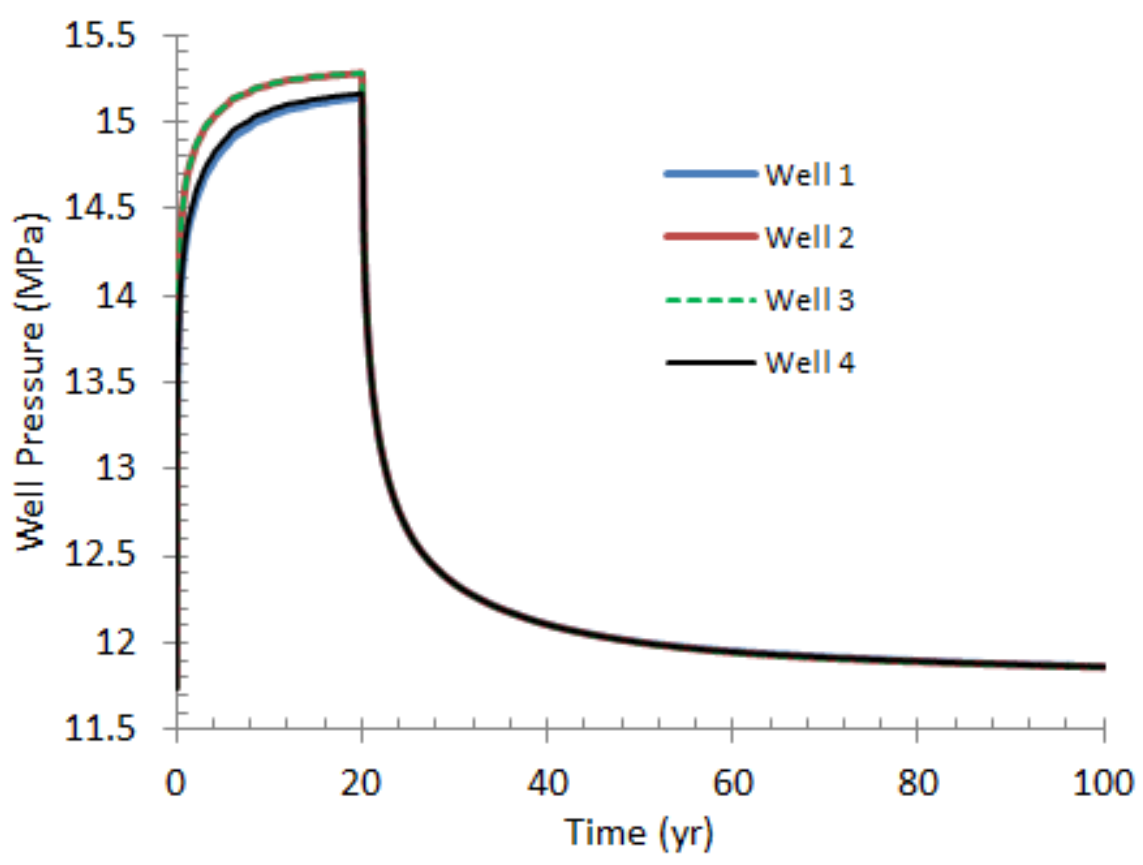

Figure 10. Well pressure (at the top of the open interval) versus time for the four injection wells. 

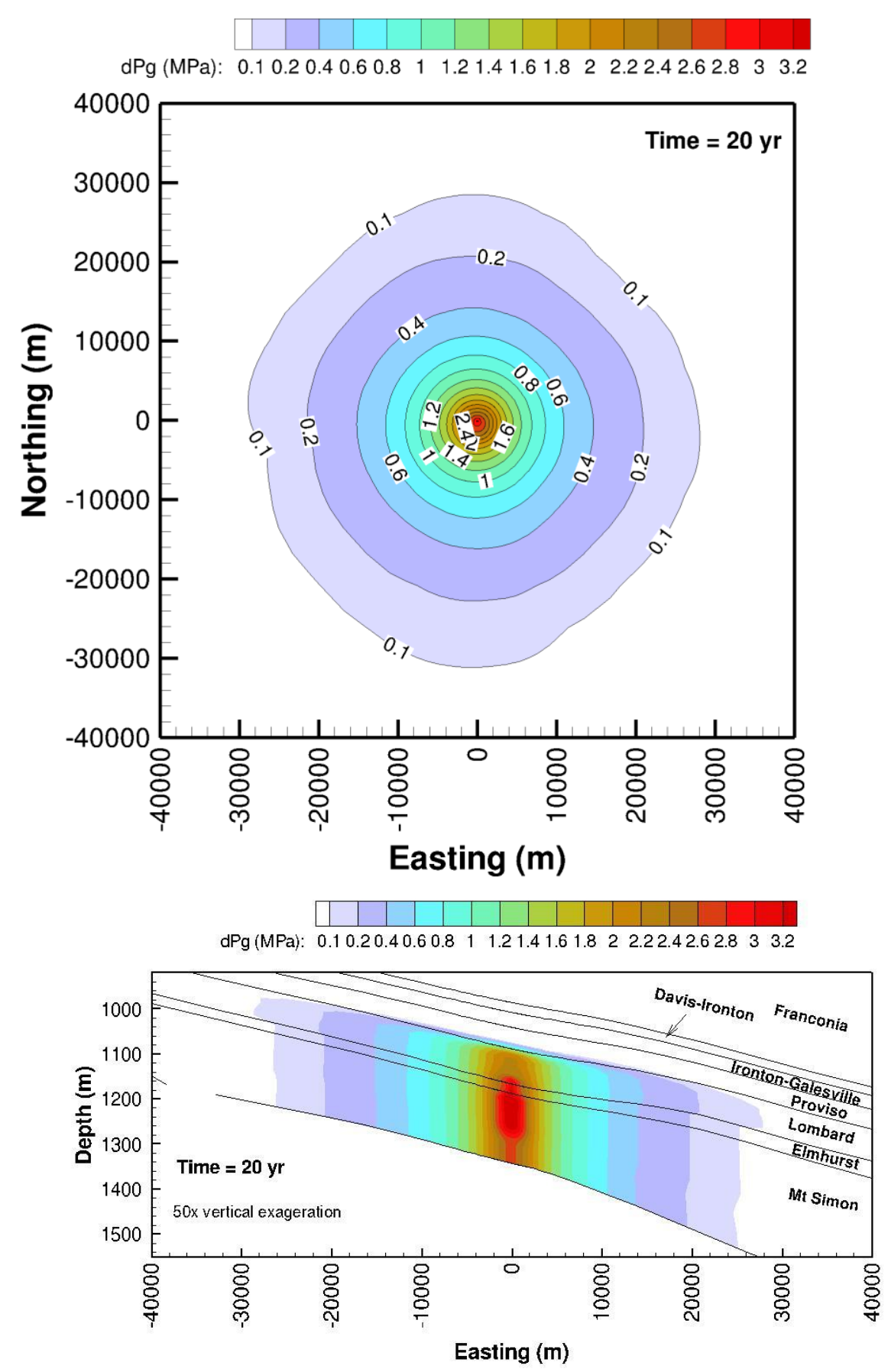

Figure 11. $\Delta \mathrm{P}$ distribution at (a) $t=20$ years, and (b) $t=70$ years at the top of the reservoir in plan view (at the middle of Lombard Formation) and in the vertical cross-section through the center of the injection wells. 

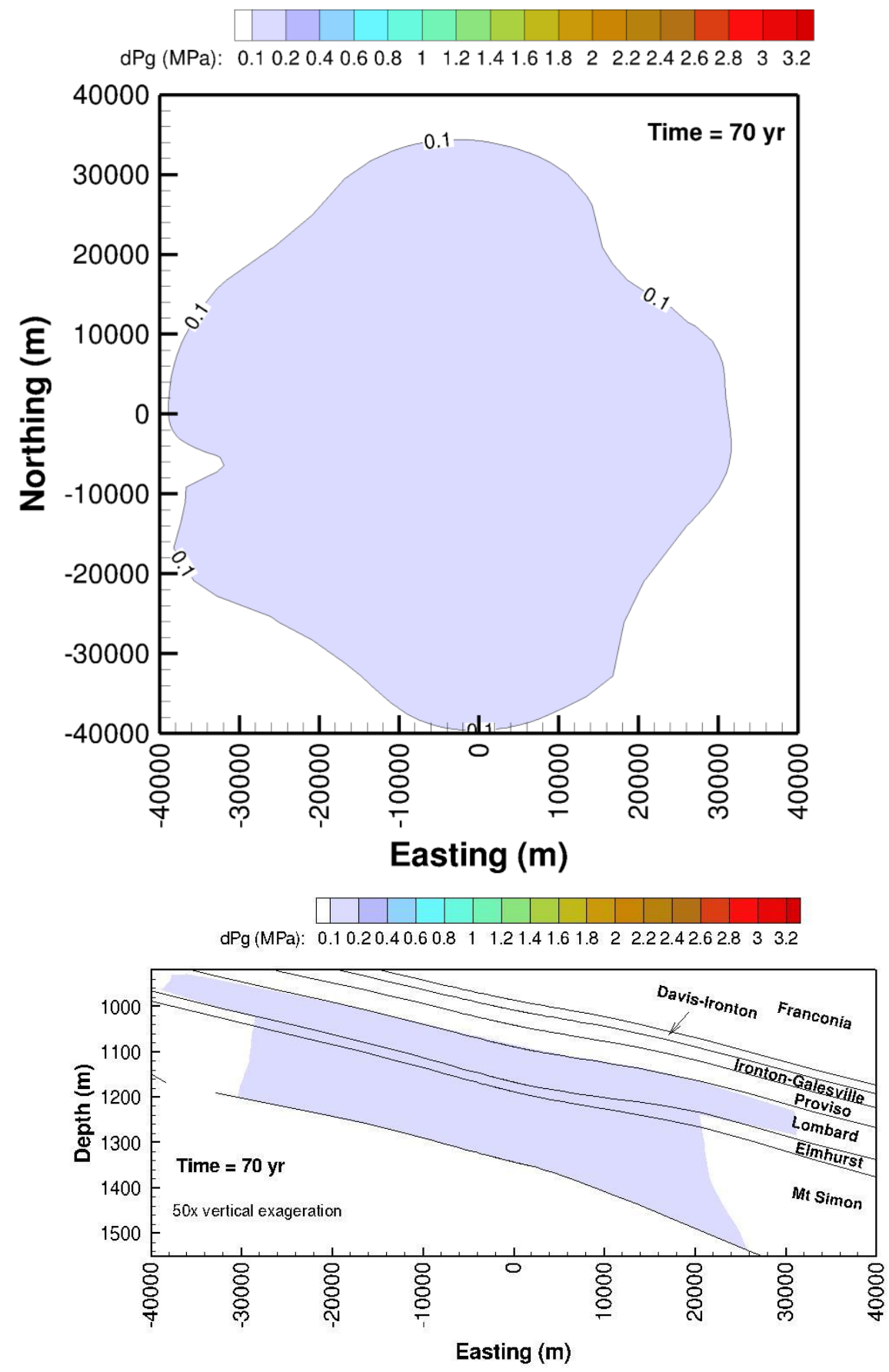

(b)

Figure 11. Continued. 


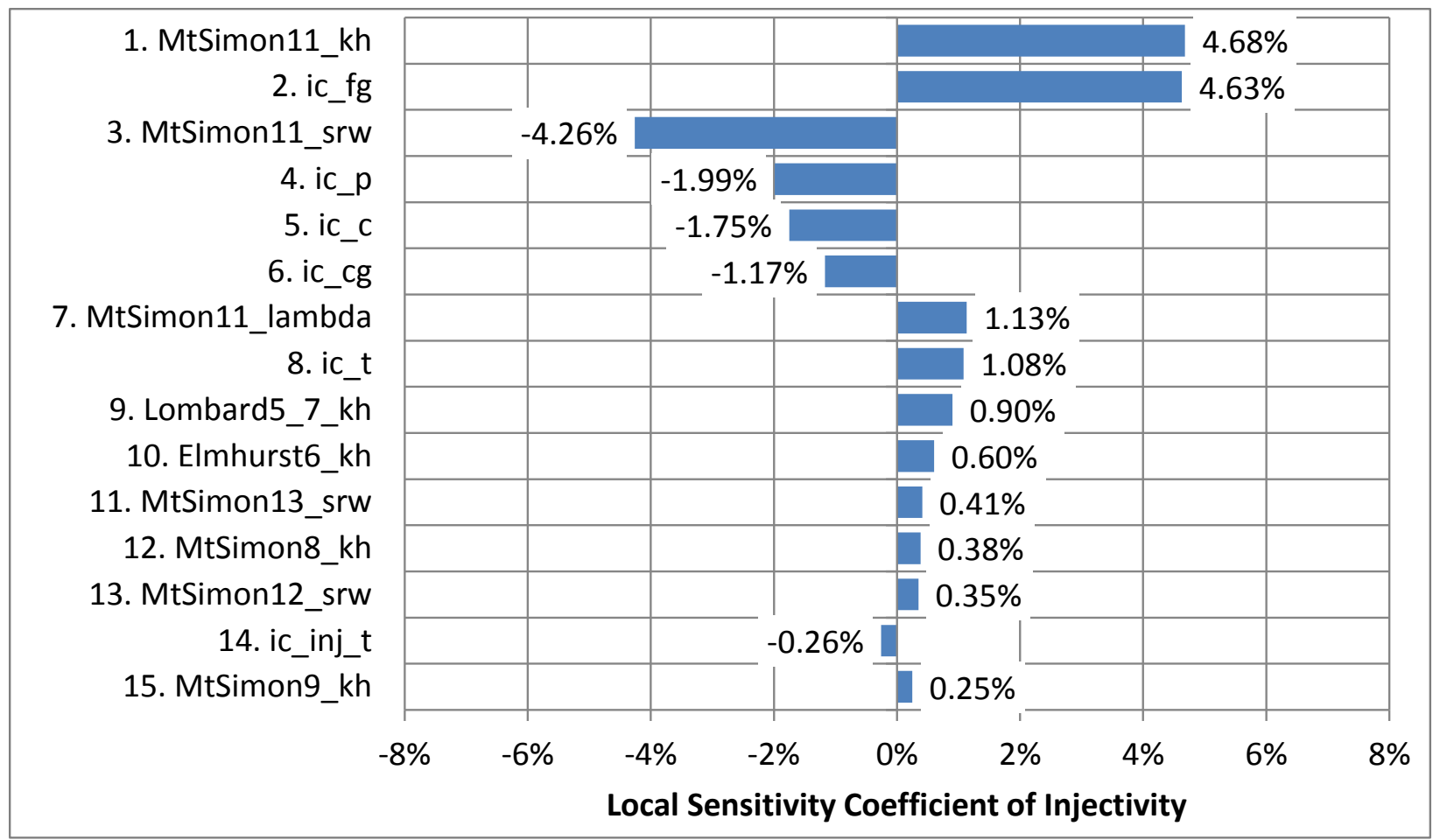

Figure 12. Injectivity local sensitivity coefficients for the 15 most sensitive inputs. The numbers in the plot represent the percent of injectivity change relative to that of the reference case. The labels in the vertical axis are the combination of the following: rank of the input, rock layer name (Table 4) or initial condition (ic), and the name of the input parameter symbol listed in Tables 5 or 6 . 


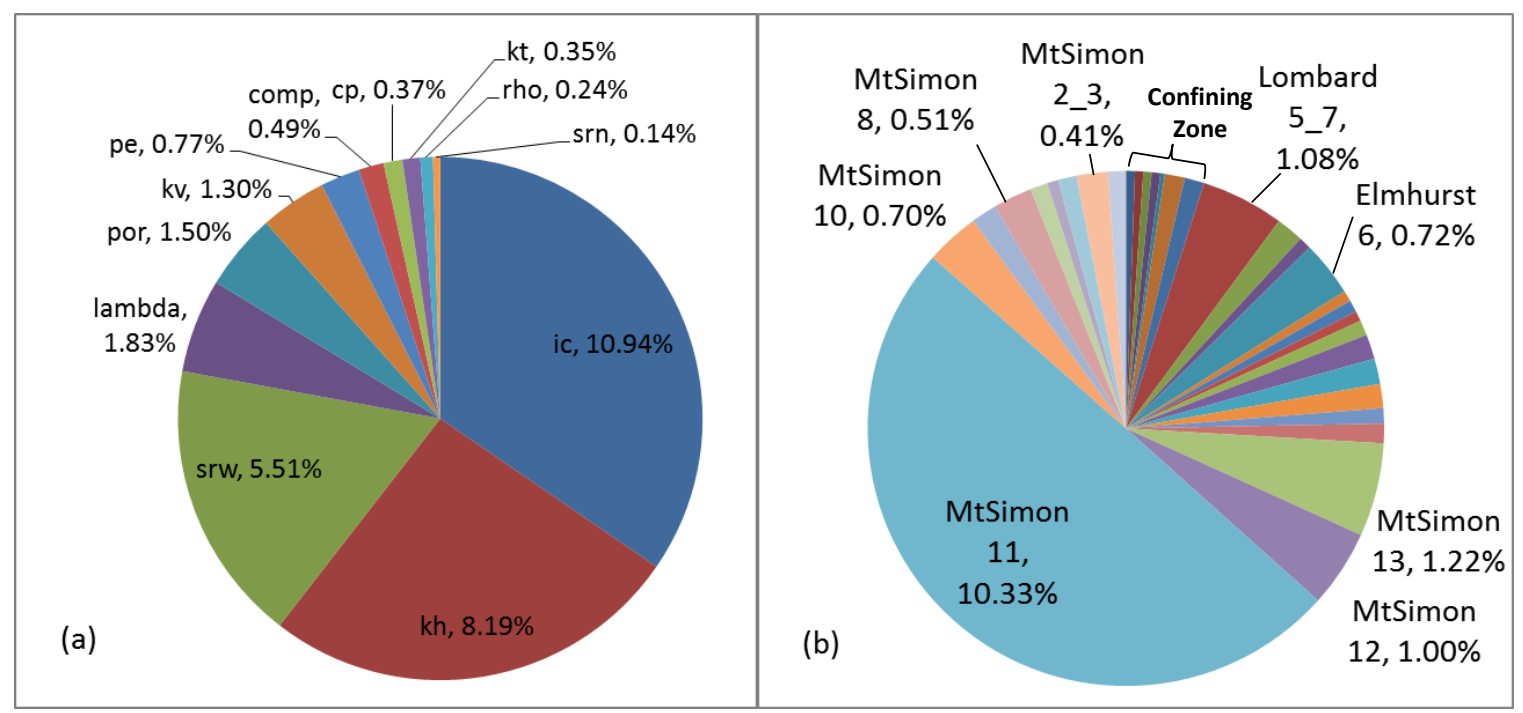

Figure 13. (a) Absolute composite sensitivity coefficients for $\mathrm{CO}_{2}$ injectivity to the 12 input parameter types. (b) Absolute composite sensitivity coefficients for $\mathrm{CO}_{2}$ injectivity to the 31 layers. The numbers in the plot represent the percent of injectivity change relative to that of the reference case. In plot (b), the names of the rock layers (Table 4) are only shown for the most sensitive layers. 


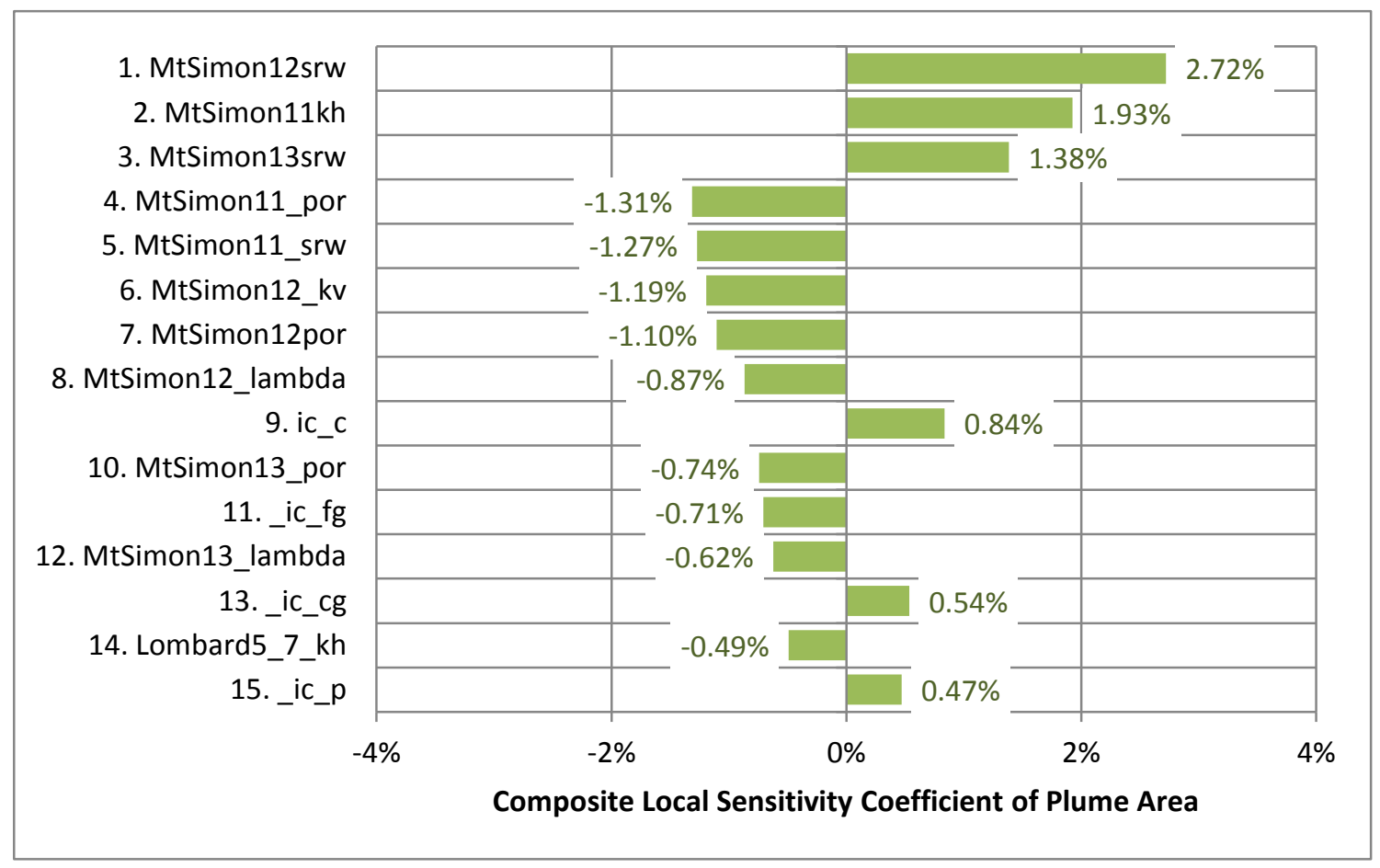

Figure 14. Plume area local sensitivity coefficients for the 15 most sensitive inputs. The numbers in the plot represent the percent of plume area change relative to that of the reference case. The labels in the vertical axis are the combination of the following: rank of the input, rock layer name (Table 4) or initial condition (ic), and the name of the input parameter symbol listed in Tables 5 or 6 . 


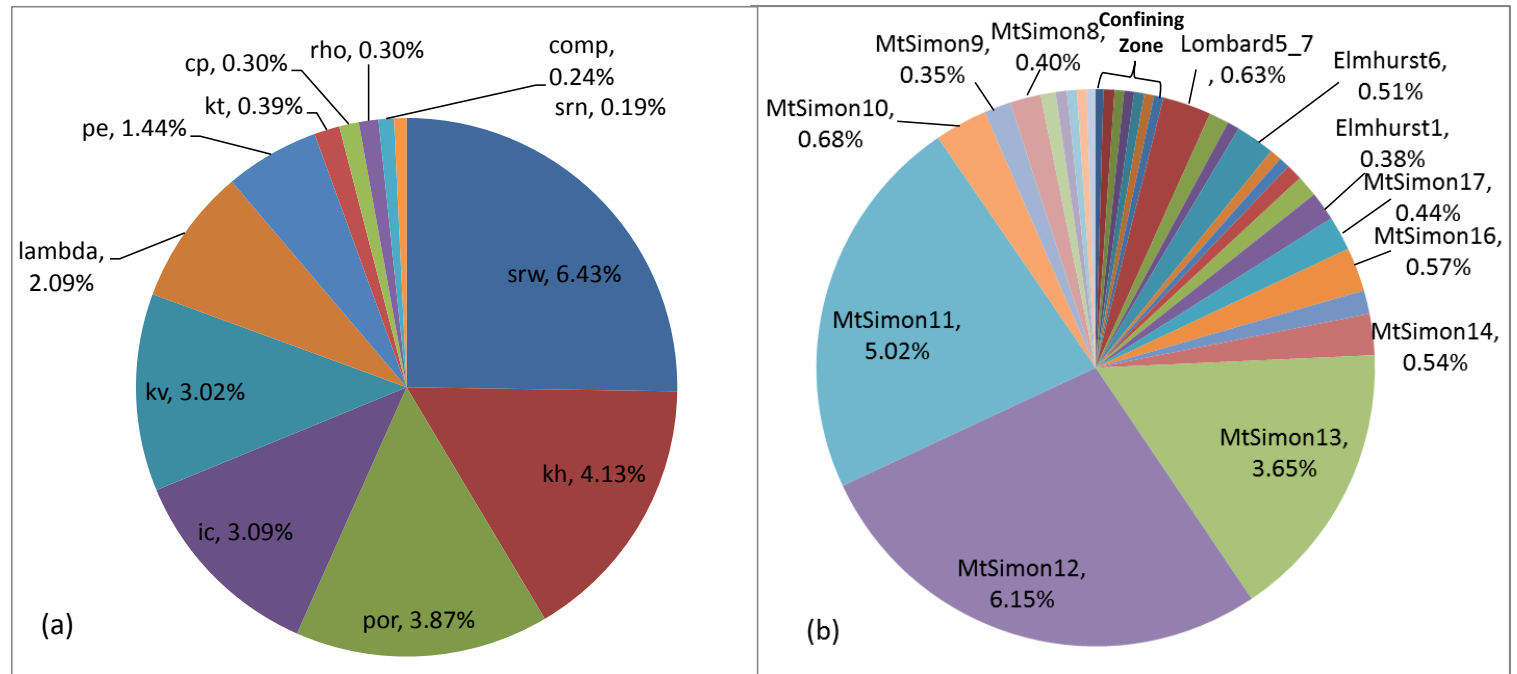

Figure 15. (a) Absolute composite sensitivity coefficients for $\mathrm{CO}_{2}$ plume area to the 12 input parameter types. (b) Absolute composite sensitivity coefficients for $\mathrm{CO}_{2}$ plume area to the 31 layers. The numbers in the plot represent the percent of plume change relative to that of the reference case. In plot (b), the names of the rock layers (Table 4) are only shown for the most sensitive layers. 